\title{
Towards a neo-configurational theory of intrinsic motivation
}

\author{
Martyna Daria Swiatczak ${ }^{1}$ (i)
}

Accepted: 24 August 2021 / Published online: 30 September 2021

(c) The Author(s) 2021

\begin{abstract}
This research seeks to improve our understanding of how intrinsic motivation is instantiated. Three motivation theories, flow theory, self-determination theory, and empowerment theory, have informed our understanding of the foundations of intrinsic motivation at work. Taken jointly, they suggest six causal factors for intrinsic motivation: (1) perceived competence, (2) perceived challenge, (3) perceived autonomy, (4) perceived impact, (5) perceived social relatedness, and (6) perceived meaningfulness. Integrating different theoretical perspectives, I employ a case-based configurational approach and conduct coincidence analyses on survey data from a German public utility to analyse the nuanced interplay of these six causal factors for intrinsic motivation. My data show that high perceived meaningfulness or high perceived autonomy is sufficient for high perceived intrinsic motivation and at least one of the two conditions must be present. Further, my findings reveal a common cause structure in which perceived impact is not a causal factor for intrinsic motivation but an additional outcome factor. Subsequent analyses shed light on possible roles of the remaining proposed causal factors by drawing a tentative causal chain structure. The results of this study enhance our understanding of the causal complexity underlying the formation of intrinsic motivation.
\end{abstract}

Keywords Intrinsic motivation · Meaningfulness · Autonomy · Impact · Configurational theorizing · Configurational comparative methods $(\mathrm{CCM}) \cdot$ Coincidence analysis $(\mathrm{CNA})$

\section{Introduction}

Intrinsic motivation - the motivation to perform an activity for its own sake, solely out of the interest, excitement, and enjoyment inherent in this activity-is crucial for individual thriving at work as well as organizational success. As such, previous studies have linked intrinsic motivation to a number of desirable outcomes in the work context such as creativity, knowledge sharing, extra-role behaviour, performance, satisfaction, and well-being (Bakker, 2008; Gagné, 2009; Gagné et al., 2015; Grant, 2008a; Howard et al., 2016; Malik et al., 2019; Van den Broeck et al., 2016; Zapata-Phelan et al., 2009).

The data collection process was conducted by the author during her previous position at the German University of Administrative Sciences, Speyer, Germany.

Martyna Daria Swiatczak

martyna.swiatczak@uib.no

1 Department of Philosophy, University of Bergen, Postboks 7805, 5020 Bergen, Norway
Paying tribute to the central role that intrinsic motivation plays in the work context, extant research has extensively examined the drivers of intrinsic motivation. While most research in this realm chooses the perspective of self-determination theory (Deci \& Ryan, 1985, 2000; Ryan \& Deci, 2017), the longer existing flow theory (Csikszentmihalyi, $1975,1990)$ and the younger empowerment theory (Conger \& Kanungo, 1988; Spreitzer, 1995; Thomas \& Velthouse, 1990), propose alternative sets of causal factors for intrinsic motivation. Less is known, however, about how the implications from the different theoretical perspectives relate to each other. Do different motivation theories describe alternative paths towards intrinsic motivation? Are some causal factors interchangeable across the theories or even redundant? Empirical studies combining multiple theoretical perspectives on intrinsic motivation barely exist (see Kowal \& Fortier, 1999 for an exception). Thus, research and practice are left with differing and partly conflicting implications from multiple theories potentially leading to confusion around the question which factors to address in order to create intrinsically motivating work environments. 
Moreover, empirical evidence on the drivers of intrinsic motivation is almost exclusively correlational in nature. To date, studies mostly concentrate on the net effects of causal factors on intrinsic motivation in the form of 'the more of X, the more of Y' (e.g. Spreitzer, 1995; van Dijke et al., 2019; Van den Broeck et al., 2016). Correlational studies, however, are not designed to shed light on the question how different causal factors interplay to create intrinsic motivation: Which factors in which combination are necessary and sufficient for intrinsic motivation? Do alternative configurations exist that lead to intrinsic motivation? This holds also true for person-centred approaches like cluster analyses (Moran et al., 2012; Van den Broeck et al., 2013) and latent profile analyses (Graves et al., 2015; Howard et al., 2016) that are increasingly being adopted in motivation research. As highly informative as these studies are in showing, inter alia, that motivation clusters including high levels of intrinsic motivation are more strongly related to need satisfaction, autonomy, social relatedness, competence, task significance (Moran et al., 2012), performance (Howard et al., 2016; Moran et al., 2012), well-being (Howard et al., 2016), job satisfaction, and commitment (Graves et al., 2015; Van den Broeck et al., 2013), they, first, do not yet concentrate on the input side of intrinsic motivation and, second, are not designed to analyse how certain causal factors may combine in order to produce an outcome of interest (for a detailed comparison between latent profile analysis and a CCM see Gabriel et al., 2018).

I address these gaps in two ways. First, I empirically investigate causal factors from three different theories of motivation within one study. In doing so, I provide a heuristic approach to overcome single-theory perspectives and link the major theories of intrinsic motivation. Second, I build upon configurational theorizing (Furnari et al., 2020) in order to investigate the causal complexity that lies behind the formation of intrinsic motivation. I therefore apply Coincidence Analysis (CNA) (Baumgartner, 2009; Baumgartner $\&$ Ambühl, 2020a) as one method from the family of configurational comparative methods (CCMs) that allows simultaneously for multiple causal factors to produce intrinsic motivation in combination (conjunctivity), multiple alternative configurations of causal factors to lead to intrinsic motivation (disjunctivity), both the presence and absence of causal factors to be potentially causal in different combinations (asymmetry), and multilevel causal influences (sequentiality) (Baumgartner \& Ambühl, 2020b; Mahoney, 2008; Misangyi et al., 2016; Ragin, 1987, 2000, 2008).

Accordingly, the contribution of this research is twofold. First, I extend previous single-theory approaches and propose how conflicting predictions from multiple theories can be resolved. Second, I provide for a neo-configurational perspective, that not only examines complex configurations of factors in the form of AND/OR combinations, but also links them causally to an outcome of interest (Baumgartner, 2009;
Furnari et al., 2020). Overall, I argue that a more nuanced view on intrinsic motivation may provide more specific guidance for organizations on how to foster intrinsic motivation among their employees and help to better adjust work environments accordingly.

\section{Theoretical background}

\section{Three theories of intrinsic motivation and their postulates}

Intrinsic motivation refers to the direct satisfaction of needs based on interest in and enjoyment of an activity ("doing what lights you up") and is typically contrasted with extrinsic motivation, the indirect satisfaction of needs based on outcomes external to the activity itself ("doing something to achieve something else") (Atkinson, 1964; Deci \& Ryan, 2000; Gagné \& Deci, 2005; Kruglanski, 1978). Accordingly, in the work context, individuals typically perceive intrinsic motivation towards tasks that are themselves interesting, enjoyable, and involving. As such, intrinsic motivation has been linked to a variety of desirable work outcomes such as creativity and innovation (Amabile, 1985, 1988; Malik et al., 2019), knowledge creation and sharing (Csikszentmihalyi et al., 1997; Gagné, 2009), cognitive flexibility and problem solving (McGraw \& McCullers, 1979), prosocial and extrarole behaviour (Bakker, 2008; Demerouti, 2006; Eisenberger et al., 2005; Gagné, 2003; Grant, 2008a), performance and engagement (Bakker, 2008; Demerouti, 2006; Gagné et al., 2015; Grant, 2008a; Hackman \& Oldham, 1976; Seibert et al., 2004; Zapata-Phelan et al., 2009), satisfaction (Bakker, 2008; Deci et al., 1989; Seibert et al., 2004), positive mood (Eisenberger et al., 2005; Fullagar \& Kelloway, 2009), and well-being (Howard et al., 2016; Van den Broeck et al., 2016).

Unlike extrinsic motivation (e.g. Burks et al., 2009; Jaworski \& Young, 1992; Langevin \& Mendoza, 2013), intrinsic motivation manages performance without creating dysfunctional effects like gambling, cheating, and free-riding or the need for any additional external resources. Thus, "by understanding the determinants of intrinsic motivation in situations as well as within persons, enormous savings of natural resources could be achieved while at the same time the quality of life could be directly improved" (Csikszentmihalyi et al., 2014, p. 123). Accordingly, substantial research has examined the sources of intrinsic motivation. More precisely, the drivers of intrinsic motivation have been investigated through the lenses of three theories: flow theory (Csikszentmihalyi, 1975, 1990; Csikszentmihalyi et al., 2017), self-determination theory (Deci \& Ryan, 1985, 2000; Ryan \& Deci, 2017), and empowerment theory (Conger \& 
Kanungo, 1988; Spreitzer, 1995; Thomas \& Velthouse, 1990).

Flow theory shows two main causal factors for intrinsic motivation: (1) perceived competence and (2) perceived challenge (Chen et al., 1999; Csikszentmihalyi, 1975, 1990; Fong et al., 2015; Keller \& Bless, 2008; Moneta \& Csikszentmihalyi, 1999; for an overview see Delle Fave et al., 2011, chapter 4.7). Self-determination theory shows that the satisfaction of three basic psychological needs, the need for (1) autonomy, (2) competence, and (3) social relatedness, predict intrinsic motivation (e.g. Andreassen et al., 2010; De Cooman et al., 2013; Olafsen et al., 2015; Richer et al., 2002). These findings are backed by meta-analyses (Slemp et al., 2018; Van den Broeck et al., 2016) and cluster analyses combined with correlational analyses (e.g. Moran et al., 2012; Warburton et al., 2020). Finally, from the perspective of empowerment theory there is evidence for four causal factors for intrinsic motivation: (1) perceived competence, (2) perceived autonomy, (3) perceived meaningfulness, and (4) perceived impact (Seibert et al., 2004; Spreitzer, 1995; for an overview see Spreitzer, 2008). Although all theories overlap to some degree, they also provide, to a substantial degree, differing and partly conflicting predictions, which is the main motivation to further investigate them in one study.

\section{Flow theory}

The original purpose underlying flow theory (Csikszentmihalyi, 1975, 1990) was to "disentangle the sources of intrinsic motivation" (Csikszentmihalyi, 1975, p. 14). Over four decades of subsequent research suggests that intrinsic motivation can be best explained through the concept of flow (Csikszentmihalyi, 1975; Csikszentmihalyi et al., 2017). Csikszentmihalyi introduced flow as the absolute absorption in an activity: an experiential state of focused concentration, unity of action and awareness, loss of self-consciousness, effortless control, and distortion of time where the enjoyment of the activity results from the activity itself (Csikszentmihalyi, 1975, 2014; Csikszentmihalyi et al., 2017; Nakamura \& Csikszentmihalyi, 2009). Due to its autotelic nature, flow is referred to as the prototypical experience of intrinsic motivation (Csikszentmihalyi et al., 2017; Deci \& Ryan, 2000) and has been empirically linked to intrinsic motivation in diverse contexts (Bakker, 2008; Eisenberger et al., 2005; Kowal \& Fortier, 1999; Moneta, 2012). The main precondition for flow lies in a balance between the challenges of an activity and the individual competences in this activity: if the challenges exceed the competences, the individual will feel anxiety, but boredom if the challenges are insufficient compared to the competences (Csikszentmihalyi, 1975, 1990; Csikszentmihalyi et al., 2017). This interplay is central to flow theory and also referred to as the "balance hypothesis" (Keller \& Bless, 2008).

As flow is a form of intrinsic motivation, the balance hypothesis can also be hypothesized as a precondition for intrinsic motivation. Indeed, experimental studies have repeatedly shown significant effects of a challenge-competence balance directly on intrinsic motivation (Keller \& Bless, 2008; Keller et al., 2011). A meta-analysis by Fong et al. (2015) further confirms the relationship between a competence-challenge balance and both flow as well as intrinsic motivation, although it shows the effect on the latter to be smaller. Elsewhere, Csikszentmihalyi (1997) and Csikszentmihalyi and LeFevre (1989) restrict the balance hypothesis and postulate that not only a balance between perceived challenges and competences is needed but only high values of perceived challenges and competences will lead to the flow experience, a model that is also referred to as the "current" model as opposed to the "original" model proposing the balance hypothesis (see for an overview Nakamura \& Csikszentmihalyi, 2009). Paying reference to both models, this study investigates all possible combinations of the presence and absence of the two causal factors (1) perceived challenge (CHA) and (2) perceived competence (COM), i.e. the presence or the absence of both factors could be revealed as causal for intrinsic motivation (in line with the "original" flow theory model) but also only the presence of both factors could be revealed as causal for intrinsic motivation (in line with the "current" flow theory model).

\section{Self-determination theory}

Self-determination theory defines intrinsic motivation, the most autonomous form of motivation along the self-determination continuum, as the pure interest, excitement, and enjoyment of performing a task (Deci \& Ryan, 2000; Gagné \& Deci, 2005; Gagné et al., 2019; Howard, et al., 2020a, 2020b). Research from the self-determination theory perspective has widely shown that the satisfaction of three basic needs, the need for competence (COM), autonomy (AUT), and social relatedness (SOC) is positively related to intrinsic motivation and more autonomously driven profiles (Moran et al., 2012). At the same time, Deci and Ryan (2000) originally ascribe the perceptions of competence and autonomy a more central role than the perception of social relatedness. They see high perceived competence and autonomy as necessary, but not sufficient: "experiences of competence and autonomy are essential for intrinsic motivation and interest, but the needs for competence and autonomy do not provide a sufficient definition of intrinsic motivation" (Deci \& Ryan, 2000, p. 233). They further argue that high perceived competence and autonomy in conjunction with high perceived social relatedness can be one sufficient 
Flow theory:

$\mathrm{COM}^{*} \mathrm{CHA} \rightarrow \mathrm{INT}$

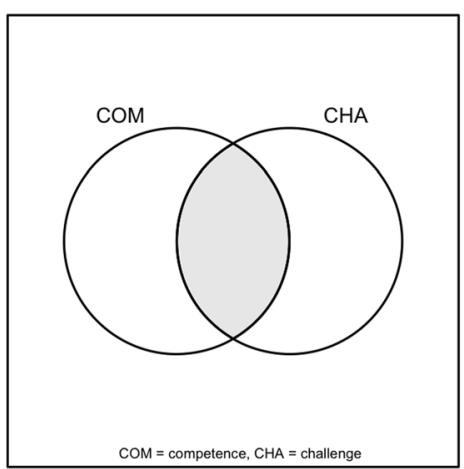

Self-determination theory:

$\mathrm{COM}^{*} \mathrm{AUT} \leftarrow$ INT

$\mathrm{COM}^{*} \mathrm{AUT}^{*} \mathrm{SOC} \rightarrow \mathrm{INT}$

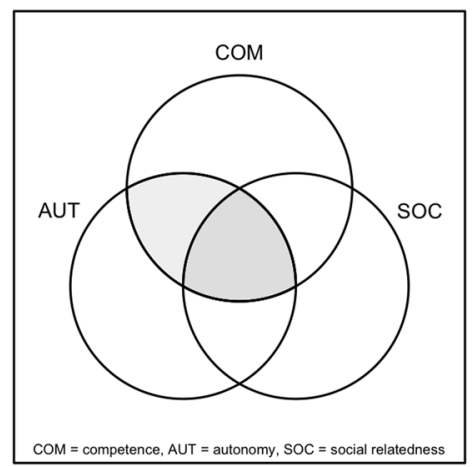

Empowerment theory:

$\mathrm{COM}^{*} \mathrm{AUT}^{*}{ }^{*} \mathrm{MP}^{*} \mathrm{MEA} \rightarrow \mathrm{INT}$

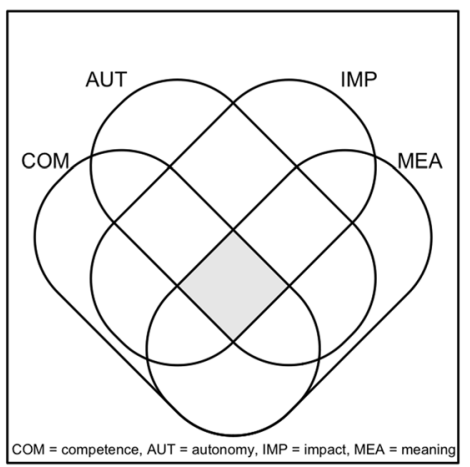

Fig. 1 Venn diagrams of all implications for the occurrence of intrinsic motivation from the perspective of flow theory, self-determination theory, and empowerment theory. Created using the R package venn, version 1.9 (Duşa, 2019)

path towards intrinsic motivation. More recently, further socalled "candidate needs" have been discussed and tested to be included in self-determination theory, such as the need for benevolence (Martela \& Ryan, 2016), nature relatedness (Baxter \& Pelletier, 2019), novelty (González-Cutre et al., 2020), and being moral (Prentice et al., 2020). However, further evidence is necessary to bring forward their inclusion as basic needs according to the inclusion criteria outlined by Ryan and Deci (2017).

Meaningfulness, by contrast, has been clearly rejected as a basic need because it is argued not to work on the same level with the other basic needs but rather to result from the satisfaction of the other basic needs (Weinstein et al., 2012). Therefore, it eventually contradicts the fifth inclusion criterion, i.e. to be a precondition and not an outcome of the growth process of intrinsic motivation (Ryan \& Deci, 2017). As such, Weinstein et al. (2012) argue that meaningfulness arises from the pursuit of intrinsic motivation. However, the authors leave room for various interpretations of causal relations between meaningfulness and intrinsic motivation, i.e. meaningfulness as a mediator between basic needs and intrinsic motivation, intrinsic motivation as a mediator between basic needs and meaningfulness, or meaningfulness and intrinsic motivation as a self-enforcing causal loop. However, neither the causal relation between meaningfulness and intrinsic motivation nor the fit of meaningfulness as a candidate need according to the inclusion criteria has been, to my knowledge, empirically investigated yet. Thus, accounting for the state-of-art in self-determination theory, this study incorporates perceived satisfactions of the three basic needs for competence (COM), autonomy (AUT), and social relatedness (SOC) as causal factors for intrinsic motivation from self-determination theory perspective.

\section{Empowerment theory}

Empowerment theory defines empowerment as the process that enhances employees' perceptions of being able to carry out their work well (Conger \& Kanungo, 1988; Seibert et al., 2004). According to Conger and Kanungo (1988), empowerment is defined as increased intrinsic task motivation and can be achieved via four perceptions, which are further empirically supported by Spreitzer (1995): competence, autonomy, meaningfulness, and impact. Only the conjunction of all four dimensions is argued to be sufficient for the outcome in the sense that the lack of any single condition will mitigate, though not completely eliminate, perceived empowerment (Spreitzer, 1995, 2008). Mitigation can, in this context, be understood as rather leading to the nonoccurrence of empowerment, referred to as intrinsic task motivation (Thomas \& Velthouse, 1990), than its occurrence. This understanding is supported by empowerment theory itself, which attempts "to specify a more nearly complete or sufficient set of task assessments that produce this motivation" (Thomas \& Velthouse, 1990, p. 667). Accordingly, in the present study I investigate four causal factors for intrinsic motivation from the perspective of empowerment theory: perceived competence (COM), perceived autonomy (AUT), perceived meaningfulness (MEA), and perceived impact (IMP).

Figure 1 illustrates the theoretical assumptions derived from all three theories as Venn diagrams. Additionally, it summarizes all theoretical implications in Boolean notation where $\left(^{*}\right)$ symbolizes a conjunction (logical AND), $(+)$ symbolizes a disjunction (logical OR), $(\rightarrow$ ) symbolizes sufficiency for an outcome, and $(\leftarrow)$ symbolizes necessity for an outcome. 
From an overarching perspective, all three theories differ in their models. Insofar as the theories frame their implications as sufficient configurations, the different implications can be synthesised as alternative paths towards intrinsic motivation. However, self-determination theory explicitly postulates that competence and autonomy are both necessary for intrinsic motivation. Thus, if this postulate holds true, all paths towards any form of intrinsic motivation need to include competence and autonomy. However, flow theory does not explicitly acknowledge autonomy as a precondition for intrinsic motivation and, thus, conflicts with selfdetermination theory in this point. In contrast, empowerment theory does not conflict with self-determination theory as it includes both competence and autonomy. Further, empowerment theory's meaning and impact could be seen as a substitute for self-determination theory's social relatedness. To shed light on how the discrepancies between the different theories can be solved, this study investigates all proposed causal factors from all three theories simultaneously.

\section{Causal factors for intrinsic motivation}

In a nutshell, self-determination theory, flow theory, and empowerment theory together suggest six causal factors for intrinsic motivation: (1) perceived competence, (2) perceived challenge, (3) perceived autonomy, (4) perceived impact, (5) perceived social relatedness, and (6) perceived meaningfulness. As all factors describe perceptions, I refer to them in the following, for simplification purposes, by their factor names only (e.g. "competence" instead of "perceived competence").

\section{Competence}

All three motivation theories see competence as a necessary causal factor for intrinsic motivation. Competence is defined as the individual assessment of one's potential to cope with a given task (Conger \& Kanungo, 1988; Gist, 1987; Spreitzer, 1995). It is being acquired through the process of gaining mastery, i.e. recognition of individual predispositions, interaction with the environment, exploration, learning, and adaptation (Deci \& Ryan, 1985). White (1959) further argues that humans have an autotelic disposition to mastery. Positive feedback on individual competence has been shown to have a positive impact on intrinsic motivation in contrast to no feedback (Boggiano \& Ruble, 1979; Deci, 1971). This, however, only holds true if feedback relates to autonomous action (Ryan, 1982), which is why self-determination theory assumes a strong connection between competence and autonomy (Deci \& Ryan, 2000).

\section{Challenge}

According to flow theory, competence only leads to flow, the prototype of intrinsic motivation, in combination with challenge. The idea of a balance between competence and challenge is consistent with previous research arguing that challenging goals only lead to higher performance, satisfaction, and motivation as long as they are achievable, i.e. within the competence scope of an individual (Freedman \& Phillips, 1985; Hom \& Maxwell, 1983; Locke \& Latham, 1990). High levels of both challenge and competence (i.e. the "current" flow theory model) have been further shown to facilitate the development of existing potentials and learning (Waterman, 1993).

\section{Autonomy}

Both self-determination theory and empowerment theory see autonomy as a necessary causal factor for intrinsic motivation, while flow theory does not explicitly acknowledge this factor. Autonomy is defined as a sense of volition and choice in initiating and regulating actions (Deci et al., 1989; Gagné \& Deci, 2005). As such, autonomy is seen as the experience of integration and freedom and an integral aspect of mental health (Deci \& Ryan, 2000; Deci et al., 1989; Sheldon \& Elliot, 1999). In the work context, autonomy refers to the initiation and continuation of work behaviours and processes like deciding upon priorities, methods, action plans, performance goals, pace, or effort at work (Ashforth, 1989; Spreitzer, 1995). A lack of autonomy was shown to lead to perceived helplessness, decreased job satisfaction, and lower levels of commitment (Ashforth, 1990), whereas the occurrence of autonomy was shown to enhance prosocial behaviour (Gagné, 2003) and knowledge sharing (Gagné et al., 2019). Moreover, assigned goals are associated with decreased levels of intrinsic motivation, while autonomously set goals are positively related to intrinsic motivation (Amabile et al., 1976; Cellar \& Barrett, 1987; Chang \& Lorenzi, 1983; Mossholder, 1980).

\section{Impact}

Empowerment theory is the only motivation theory that sees impact as a distinct causal factor for intrinsic motivation. Impact refers to the conviction that an individual can influence outcomes at work (Conger \& Kanungo, 1988; Spreitzer, 1995). Thus, impact is the belief that individual behaviour is "making a difference" in the accomplishment of work tasks and in producing intended effects (Thomas \& Velthouse, 1990). As such, impact is closely related to autonomy but not identical with it. While autonomy describes the freedom when exercising work activities, impact describes the controllability of work outcomes. Ashforth (1990) shows, 
however, that both concepts correlate. More precisely, Ashforth (1990) sees autonomy as a precondition of impact. This would imply a separate causal chain from autonomy to impact and possibly further to intrinsic motivation that empowerment theory does not acknowledge as it puts autonomy and impact on the same level despite drawing on Ashforth's (1990) work. The lack of impact is defined as helplessness (Martinko \& Gardner, 1982), "the cognition that one lacks control over work outcomes; it is the realization or internalization of a lack of autonomy and participation" (Ashforth, 1989, p. 233). Lindsley et al. (1995) further show that helplessness can undermine competence and lead to actions of allying oneself with others at work in order to increase impact. On the other hand, Drake et al. (2007) show that impact positively influences overall work motivation. Proponents of self-determination theory sometimes propose impact as one component of competence. For example, Weinstein et al. (2012) refer to competence as a compound of two aspects: "being effective and having an impact on one's environment" (Weinstein et al., 2012, p. 98). In contrast, the items by Van den Broeck et al. (2010) separate competence from impact in line with empowerment theory.

\section{Social relatedness}

Social relatedness describes the degree of being connected to others, to care for each other and to feel affection for each other (Baumeister \& Leary, 1995; Deci \& Ryan, 2000). Anderfuhren-Biget et al. (2010) define two components of social relatedness at work: relationships to other organizational members and mutual appreciation of one's work. Selfdetermination theory, as the only theory of intrinsic motivation, proposes social relatedness as a causal factor for intrinsic motivation. In their earlier work, however, Deci and Ryan (1985) do not yet integrate social relatedness, while Ryan and Deci (2000) argue that if social relatedness occurs together with autonomy and competence, this combination is sufficient for intrinsic motivation. In their argumentation, social relatedness is not necessary. It is rather one possible complement to autonomy and competence. Gagné and Deci (2005) further argue that social relatedness does not directly impact intrinsic motivation but rather promotes further internalization processes. This means that if individuals feel socially related, they will more likely accept external values as their own, which allows a shift from controlled motivation to more autonomous forms of motivation. However, more recently research has shown that the satisfaction of the need for social relatedness is fairly strongly related to intrinsic motivation (Van den Broeck et al., 2016).

\section{Meaningfulness}

Finally, meaningfulness is defined as "the value of the task goal or purpose, judged in relation to the individual's own ideals or standards" (Thomas \& Velthouse, 1990). As such, the presence or absence of meaningfulness is the result of a fundamental assessment of work tasks pursuant to individual beliefs and values and, thus, can change over time. Over the years, leading motivational researchers stress how human beings are driven to perform work that they assess as meaningful (Alderfer, 1972; Grant, 2008b; Herzberg, 1966; Maslow, 1954, 1971; McGregor, 1960; Nielsen et al., 2020; Rogers, 1961; Rosso et al., 2010). Frankl (1959) even declares the desire for meaning as the basic motivation for human life itself. On a different note, Frankl (1959) proposes that encounters with other people provide a sense of meaning to individuals, so that a close relationship between meaningfulness and social relatedness could be assumed. In the work motivation context, Maslow (1971) argues that individuals who do not see their work as meaningful cannot develop their full potential. Accordingly, the quality of meaningfulness at work reflects how much mental or emotional energy an individual is willing to invest in their activities. The lack of meaningfulness at work results in apathy, whereas its presence is associated with commitment, involvement, concentration of energy, and overall intrinsic motivation (Spreitzer, 1995; Thomas \& Velthouse, 1990).

Although, in contrast to empowerment theory, neither self-determination theory nor flow theory explicitly list meaningfulness as a precondition for intrinsic motivation, both self-determination theory and flow theory still acknowledge the important role that meaningfulness plays in the creation of intrinsic motivation. More precisely, self-determination theory proposes that the satisfaction of the three basic needs creates meaningfulness although there does not yet exist empirical evidence for this claim (Weinstein et al., 2012). Similarly, flow theory repeatedly refers to activities in which an individual experiences intrinsic motivation via flow as enjoyable and meaningful (Csikszentmihalyi, 1975, 1999). Especially deep-flow activities are argued to give meaning to a person's whole life (Csikszentmihalyi, 1975). In contrast, a study by Fullagar and Kelloway (2009) shows that task identity, defined as the degree to which a job has a meaningful impact on other people (Hackman \& Oldham, 1975), is no significant predictor of between-group variance in flow. However, Engeser and Baumann (2016) show that outcome importance, a construct that significantly overlaps with meaningfulness, is positively related to flow at work. 


\section{Method}

\section{Sample and procedure}

For the empirical investigation, I used survey data from 70 individual employees from one German public utility. I conducted the survey, that was directed towards all 211 employees, between August and October 2018. I sent an email including a link to the online survey to all employees with email access via their organisational email accounts. Additionally, a paper version was offered to three employees without email access. The paper version included a stamped, self-addressed envelope to increase the likelihood of a reply. To maximize online response rates, three reminders were sent two, four and six weeks after the initial mailing. Moreover, the survey was supported by the public utility`s CEO and Human Resource Manager. An opt-out option was offered at any time, which 12 employees chose. Overall, I received 124 valid responses (response rate: 59\%). As CCMs do not allow for any lacking data, which means that if one employee left only one factor blank, the whole case needed to be excluded, 70 cases finally classified for the analyses. In general, given 6 causal factors, 64 cases $\left(2^{\mathrm{k}}\right.$ cases where $\mathrm{k}$ is the number of analysed causal factors) are regarded as the minimum number of cases required for a CCM investigation, which is slightly overachieved by the 70 cases in my analysis. Of the 70 cases, 25 were female and 45 male employees. The cases comprised all age groups from below 26 years to above 56 years. 20 cases were employees in leadership positions.

I chose a single organisation for the investigation because a CNA, like other CCMs, requires homogeneity as a background assumption (Baumgartner \& Ambühl, 2020a; BergSchlosser \& De Meur, 2009). Homogeneity refers to an unmeasured causal background in which every confounder is constant in all investigated cases. In the context of CCMs, a confounder is understood as a cause that does not act via any of the measured causal factors. I further argue that factors that usually vary within one organisation, such as e.g. hierarchical level, are most likely on the causal path to intrinsic motivation and, thus, act via measured causal factors that I integrated in my analyses. Therefore, these factors do not represent confounders and must necessarily vary for this study. For example, having a leadership position or not can have an impact on the degree of autonomy that an individual perceives at work. As leadership position acts via autonomy and autonomy is measured in my study, this factor is not a confounder and therefore must vary. Overall, I assume the highest homogeneity for my study in a single organisation. Moreover, to better understand the work conditions and causal mechanisms within the investigated organisation, extensive case knowledge was gained during different research projects within the same public utility between 2016 and 2018.

\section{Measures and calibration}

Items for measuring all constructs were derived from extant literature and are based on validated scales. However, the various scales stem from different studies and have been subject to different degrees of prior empirical research. Moreover, most scales were validated in different contexts and not all scales were validated in the German language. Thus, I followed a thorough survey creation process, adjusted the measurement model and reassessed the psychometric properties of the final measurement instrument. As a relatively high number of constructs was measured, following Furr (2011), items that covered the same definitory dimensions were shortened in order to avoid the survey to be too lengthy. Moreover, unambiguous, comprehensible formulations were ensured. The order of the items and the number of items per group of questions in the survey was chosen so as to prevent response biases like central tendency bias, question order biases, or carry-over effects. Additionally, the survey went through a two-step pre-test procedure. In the first step, a series of pre-tests on the final scales was conducted with scholars in the field. In the second step, the author and one further researcher conducted cognitive pretesting (Lenzner et al., 2016) in a comparable public utility between May and June 2018.

To measure intrinsic motivation, I used all three items of the Multidimensional Work Motivation Scale, which has been extensively validated in seven languages by Gagné et al. (2015) (e.g. "I put efforts into my job because I have fun doing my job"). Its German version was obtained from the validation study's first author. Competence was measured based on scales by Spreitzer (1995) and Van den Broeck et al. (2010) (e.g. "I am confident about my ability to do my job"). The German translation was based on Staufenbiel and Hartz (2000) and von Collani and Schyns (1999). Challenge was measured based on a German scale validated by Weyer et al. (1997) (e.g. "My work activities are challenging"). Autonomy was measured based on scales by Van den Broeck et al. (2010), Spreitzer (1995), and its validation in German language provided by Staufenbiel and Hartz (2000) (e.g. "I can decide on my own how to go about doing my work"). Impact was measured based on scales by Spreitzer (1995) and its German version by Staufenbiel and Hartz (2000) (e.g. "I have control over what happens at my work"). In addition, I used the original scale for helplessness at work provided by Ashforth (1989). Social relatedness was measured based on Van den Broeck et al. (2010) (e.g. "At work, I feel part of a group"). Finally, meaningfulness was measured based on scales by Spreitzer (1995) and its German version 
Table 1 Summary of skewness ratios (percentage of cases $>0.5$ ) and descriptive statistics

\begin{tabular}{|c|c|c|c|c|c|c|c|}
\hline \multirow[t]{2}{*}{ Factor } & \multicolumn{3}{|c|}{ Crossover points } & \multicolumn{4}{|c|}{ Descriptive statistics } \\
\hline & $3.5(\%)$ & $4.5(\%)$ & $5.5(\%)$ & Min & Mean & Median & Max \\
\hline Intrinsic motivation & 84.29 & 58.57 & 15.71 & 1.667 & 4.559 & 5.000 & 6.000 \\
\hline Competence & 97.14 & 78.57 & 42.86 & 3.333 & 5.195 & 5.333 & 6.000 \\
\hline Challenge & 62.86 & 30.00 & 2.86 & 2.000 & 4.071 & 4.000 & 6.000 \\
\hline Autonomy & 80.00 & 44.29 & 7.14 & 1.000 & 4.162 & 4.333 & 6.000 \\
\hline Impact & 74.29 & 35.71 & 2.86 & 1.000 & 4.081 & 4.250 & 6.000 \\
\hline Social relatedness & 84.29 & 52.86 & 22.86 & 1.500 & 4.714 & 5.000 & 6.000 \\
\hline Meaningfulness & 88.57 & 60.00 & 18.57 & 1.667 & 4.621 & 4.667 & 6.000 \\
\hline Min & 62.86 & 30.00 & 2.86 & 1.000 & 4.071 & 4.000 & 6.000 \\
\hline Mean & 81.63 & 51.43 & 16.12 & 1.738 & 4.486 & 4.680 & 6.000 \\
\hline Median & 84.29 & 52.86 & 15.71 & 1.667 & 4.559 & 5.000 & 6.000 \\
\hline Max & 97.14 & 78.57 & 42.86 & 3.333 & 5.195 & 5.333 & 6.000 \\
\hline
\end{tabular}

Bold values indicate skewness ratios between $20 \%$ and $80 \%$ provided by Staufenbiel and Hartz (2000) (e.g. "The work I do is important to me").

I assessed the psychometric properties of the final measurement instrument and further enhanced the model fit based on confirmatory factor analyses. While the original measurement model's fit was not satisfactory (CFI $=0.846$, $\mathrm{TLI}=0.816$, RMSEA $=0.090, \mathrm{SRMR}=0.099)$, the adjusted measurement model achieved satisfactory fit $(\mathrm{CFI}=0.942$, $\mathrm{TLI}=0.928$, RMSEA $=0.062, \mathrm{SRMR}=0.076)$. To adjust the model, I removed items with low communality $\left(\mathrm{R}^{2}<0.35\right)$ one by one as long as theoretical reasons or pretesting knowledge supported their removal. The removed items were equivalent to the items with high modification indices (mi $>10)$. In total, 4 items were dropped (Imp4, Soc3, Aut2, Cha2). Two of the dropped items were reverse coded (Soc3, Aut2). To further assess convergent validity, I calculated the average variance extracted (AVE) for each construct. All AVE values exceeded the recommended 0.5 threshold (Fornell \& Larcker, 1981) and scored between 0.585 and 0.7907 indicating adequate convergent validity. Appendix 1 shows the final measurement model and its model fit. ${ }^{1}$ As the study's $\mathrm{N}$ is comparatively small $(\mathrm{N}=70)$, I additionally tested the model fit on a subset of the model leaving out one entire construct (IMP). Creating this specific subset of the original model allowed for testing the model on a slightly larger $\mathrm{N}(\mathrm{N}=99)$. The confirmatory factor analysis on the subset model revealed a comparably satisfactory fit $(\mathrm{CFI}=0.957, \mathrm{TLI}=0.944$, $\mathrm{RMSEA}=0.061$, SRMR $=0.064)$.

The last step of the data preparation process was the socalled calibration. As CNA is based on Boolean algebra, it analyses the relationship between sets of cases and, thus,

\footnotetext{
1 The original and adjusted scales in German language can be obtained by contacting the author.
}

requires allocating membership scores to cases-a process called calibration (Ragin, 2008). To do so, the collected data was used to build numerical scores of each construct. All items were measured on a six-point scale with verbal descriptions as anchors for the endpoints ranging from $1=$ "does not apply at all" to $6=$ "fully applies". Accordingly, means ranged from 1 to 6 . Based on the means, direct calibration (Schneider \& Wagemann, 2012, pp. 35-38) was finally used to assign set memberships ranging from 0 (full non-membership, e.g. employees that do not perceive themselves as intrinsically motivated) to 1 (full membership, e.g. employees that perceive themselves as fully competent) with a crossover point at 0.5 (e.g. employees who perceive themselves as neither autonomous nor not autonomous) to all cases. Calibration is one of the most demanding steps in CCMs and determines the subject of the analysis. One could for example calibrate both sets "employees who perceive their work as rather autonomous" and "employees who perceive their work as highly autonomous" based on the same survey data. For both sets full non-membership (0) would be assigned to the raw mean value of 1 and full membership (1) to the raw mean value of 6 . However, the crossover point (0.5) for the first set would be assigned to the middle of the scale (3.5) and for the second set to an upper point of the scale (e.g. 4.5). Note that both sets would imply different interpretations of the results. As such, the process of calibration is a core feature of any CCM and advised to be based on substantive and theoretical knowledge. For the study of intrinsic motivation, I argue that there exist three theoretically sound options to define sets based on the theoretical background: (1) occurrence of a factor with a crossover point at 3.5, (2) high values of a factor with a crossover point at 4.5 and (3) very high values of a factor with a crossover point at 5.5. On a six-point scale, all of the possible crossover points have a clear-cut meaning, i.e. participants categorized their answers as belonging to the 
upper half of the scale (3.5), to the upper third of the scale (4.5), or to the upper sixth (5.5) of the scale.

In addition to substantive and theoretical knowledge, skewness is an important empirical criterion for determining calibration thresholds for CCMs as skewed data exacerbate limited diversity and may distort parameters of fit or the solution itself (Glaesser \& Cooper, 2014; Oana et al., 2021; Thomann \& Maggetti, 2020). Skewness ratios, i.e. the percentage of cases with higher than 0.5 membership values in a given set (Oana et al., 2021, p. 44), were calculated for all theoretically sound cross-over points of 3.5, 4.5, and 5.5. Table 1 summarizes the corresponding skewness ratios and descriptive statistics.

In line with previous studies (e.g. Gabriel et al., 2018), a general positivity bias with regards to response values can be observed. Especially competence is left skewed. In contrast, challenges are generally estimated lower than the average of all other items and, thus, right skewed. Given the skewness ratios in Table 1, a mean of 4.5 was chosen for all factors to reflect the diversity of the analysed cases (Berg-Schlosser et al., 2009). This procedure results in an acceptable skewness range from $30.00 \%$ to $78.57 \%$ with approximately $20 \%$ to $80 \%$ being regarded as not problematic (Oana et al., 2021, p. 44). The derived sets depict groups of employees that perceive the given factors as high. Thus, the study's results are bound to exactly this definition.

\section{Coincidence analysis: configurational comparative approach}

As CNA is a comparatively new method, I will briefly introduce it in this chapter. This cannot be an extensive introduction to the method. However, the given references provide further guidance. Readers already acquainted with CNA or not interested in CNA might chose to skip this part.

CCMs are techniques used to identify complex causal structures between exogenous factors and one or more endogenous factors (outcomes) based on Boolean algebra. What drives CCMs, is "to allow systematic cross-case comparisons while at the same time giving justice to within-case complexity" (Rihoux \& Ragin, 2009, p. xviii) and embracing causal complexity, i.e. conjunctivity, disjunctivity (also referred to as equifinality), asymmetry, and sequentiality (Baumgartner \& Ambühl, 2020b; Mahoney, 2008; Misangyi et al., 2016; Ragin, 1987, 2000, 2008). In order to enable a systematic comparison of complex cases, those cases are transformed into configurations, i.e. specific combinations of factor values that potentially produce an outcome of interest (Rihoux \& Ragin, 2009, p. xix). These configurations are modelled as conjunctions ("AND", symbolized with "*”) and disjunctions ("OR", symbolized with "+") of factor values and further minimized.
What differentiates CNA from other CCMs is its power to derive redundancy-free Boolean dependencies and, thus, to produce solutions that can be causally interpreted as difference-makers in a certain context (Baumgartner \& Falk, 2019; Mackie, 1974). As such, CNA searches for rigorously minimized dependency structures of sufficiency and necessity of one or more causally modelled outcomes without relying on counterfactual reasoning. Moreover, CNA is the only CCM that is originally designed to allow for more than one endogenous factor and is therefore able to detect causal chains and common cause structures (Baumgartner \& Thiem, 2015; Haesebrouck, 2019). While already successfully applied e.g. in health science (e.g. Whitaker et al., 2020; Yakovchenko et al., 2020), CNA is still an innovative methodological approach in behavioural science. It applies a minimization algorithm custom-built for causal modelling based on a regularity theory of causation, i.e. Mackie's (1974) INUS-theory of causation (Baumgartner, 2009, 2015). According to the INUS-theory, $X$ being a cause of $\mathrm{Y}$ means that $\mathrm{X}$ is a Boolean difference-maker for $\mathrm{Y}$, which holds if, and only if, the analysed data contain at least two cases with varying $\mathrm{Y}$-values such that only a variation in $\mathrm{X}$ can account for the variation in $\mathrm{Y}$ (because other causes of $\mathrm{Y}$ are constant). Consequently, $\mathrm{X}$ cannot be eliminated from a causal model of $Y$ without taking on reduced model fit. In contrast, every factor that can be eliminated from a solution formula without lowering its model fit makes no difference to the outcome. Accordingly, CNA strives for highest possible parsimony to ensure that models only contain difference-makers. As such, this method is particularly suitable to investigate intertwined, complex, and at the same time causally relevant configurations leading to intrinsic motivation.

Just as solutions derived by CCMs represent configurations of different factor values, so do leading social science theories use AND- and OR-combinations to structure concepts and build up models as causal combinations (Goertz, 2006, p. 338; Ragin, 1987, p. 118). For example, self-determination theory originally states that the occurrence of autonomy AND competence is necessary (but not sufficient) for intrinsic motivation and together with the occurrence of social relatedness (autonomy AND competence AND social relatedness) they are sufficient for intrinsic motivation (Deci \& Ryan, 2000). At the same time, self-determiantion theory acknowledges that there can also be other sufficient combinations for intrinsic motivation that could be added via an OR-combination. In general, CCM solutions are particularly suitable to be compared with theoretical hypotheses that can be modelled as Boolean functions (Oana et al., 2021, pp. 160-166; Oana \& Schneider, 2018), which holds true for all three analysed theories of intrinsic motivation. In order to inform a neo-configurational theory of intrinsic motivation at work this study does not only account for different configurations leading to intrinsic motivation but also broadens 
Table 2 CNA of complete model: asf for INT

\begin{tabular}{llll}
\hline asf & Consistency & Coverage & Complexity \\
\hline AUT + MEA $\leftrightarrow$ INT & 0.840 & 0.945 & 2
\end{tabular}

$\mathrm{O}=\mathrm{INT} \mid \mathrm{C}_{\mathrm{INT}}=\{\mathrm{COM}, \mathrm{CHA}, \mathrm{AUT}, \mathrm{SOC}, \mathrm{MEA}, \mathrm{IMP}\}$

the view from a single-theory perspective to a multi-theory perspective.

\section{Analyses and results}

\section{Coincidence analysis of six causal factors from three theories}

For the analyses, I used the R packages cna, version 3.2.0 (Baumgartner \& Ambühl, 2020b) and additionally, for further examination and graphical representation, the $\mathrm{R}$ packages SetMethods, version 2.6 (Oana \& Schneider, 2018) and QCA, version 3.13 (Dușa, 2019). As this study focuses on explaining causal configurations for intrinsic motivation, intrinsic motivation (INT) is assumed as the main outcome factor. In addition and as previous work points to autonomy as a causal factor for impact (Ashforth, 1990), impact (IMP) is modelled as the second outcome factor. At the same time, there is evidence that impact is a causal factor for intrinsic motivation (Spreitzer, 1995). Thus, impact is ordered before intrinsic motivation which means that the cna() function assigns a set of five potential causal factors $(\mathrm{COM}=$ competence, $\mathrm{CHA}=$ challenge, $\mathrm{AUT}=$ autonomy, $\mathrm{SOC}=$ social relatedness, $\mathrm{MEA}=$ meaningfulness) to impact and a set of six potential causal factors $(\mathrm{COM}=$ competence, $\mathrm{CHA}=$ challenge, $\mathrm{AUT}=$ autonomy, $\mathrm{SOC}=$ social relatedness, $\mathrm{MEA}=$ meaningfulness and $\mathrm{IMP}=\mathrm{impact})$ to intrinsic motivation. From there, the CNA protocol proceeds as follows (Baumgartner \& Ambühl, 2020b):

In the first stage, the CNA algorithm builds a set of potential outcomes $\mathrm{O}=\{\mathrm{INT}, \mathrm{IMP}\}$ and assigns a set of potential cause factors to every potential outcome while accounting for the provided ordering, in this case: $\mathrm{C}_{\mathrm{IMP}}=\{\mathrm{COM}, \mathrm{CHA}$, AUT, SOC, MEA $\}, \mathrm{C}_{\mathrm{INT}}=\{\mathrm{COM}, \mathrm{CHA}, \mathrm{AUT}, \mathrm{SOC}, \mathrm{MEA}$, IMP .

In the second stage, a set of minimally sufficient conditions (msc) is built for each potential outcome. To do so, the CNA algorithm follows a bottom-up approach first checking single factor values for their sufficiency. Sufficiency is assumed when the consistency, i.e. the degree to which the behaviour of an outcome obeys a model (Baumgartner \& Thiem, 2015), equals or is above the defined consistency threshold. Reasonable consistency and coverage thresholds are 0.75-0.85 (Baumgartner \& Ambühl, 2020b). For every single factor that is not found to be sufficient, one additional potential causal factor is added, and their conjunctions are tested for sufficiency. This is systematically repeated for all factors in the data if, and only if, no less complex conjunction is found to be sufficient. The so derived set of msc is then passed to the next stage.

In the third stage, atomic solution formulas (asf) are derived by checking all msc elements for their necessity for the outcome. Necessity is assumed when the coverage threshold is met while coverage refers to the degree to which a model accounts for the behaviour of the corresponding outcome (Baumgartner \& Thiem, 2015). Thus, asf meet both the defined consistency as well as coverage thresholds. If, and only if, single msc elements do not meet these criteria, then disjunctions of msc are tested systematically. Again, more complex disjunctions are only built and tested if no less complex disjunctions of msc elements are found to be necessary.

Finally, a set of complex solution formulas (csf) is built encompassing all atomic solution formulas for the different potential outcomes. In this step, causal chains as well as common cause structures are represented.

Table 2 summarizes the asf for the outcome factor intrinsic motivation (consistency threshold $=0.8$, coverage threshold $=0.85$ ) with the highest model fit and the lowest complexity of all derived asf. Lowest complexity is chosen because CCMs generally run the risk of overfitting (ArelBundock, 2019; Parkkinen \& Baumgartner, 2021), a risk that is limited by low complexity solutions.

The solution shows that high autonomy or meaningfulness is sufficient and their disjunction necessary for high intrinsic motivation to occur. Figure 2 additionally shows a graphical representation of this solution including all analysed cases and their memberships in the solution as well as in the outcome. Confirming the high consistency level, it shows how most cases are distributed on the diagonal or below. Only one case lies in the first quadrant marking it as a deviant case (1054) for the sufficiency statement. This case, however, is rather close to the second quadrant and, thus, close to belonging to the solution formula.

The sufficiency of high autonomy for high intrinsic motivation is supported by two of the three theories, empowerment theory and self-determination theory and supports the central role that self-determination theory assigns to autonomy. Indeed, self-determination theory, as the name says, is built around the concept of self-determination, a concept that is very close and oftentimes used interchangeably to autonomy (Deci \& Ryan, 2000). However, meaningfulness is rather underrepresented in the theories of intrinsic motivation. Only empowerment theory proposes meaningfulness as a causal factor. But a closer look at the flow theory shows that it implicitly acknowledges the concept of meaningfulness from its beginnings. Csikszentmihalyi (1990) defines 
Table 3 CNA of complete model: asf for IMP

\begin{tabular}{llll}
\hline asf & Consistency & Coverage & Complexity \\
\hline AUT $\leftrightarrow$ IMP & 0.835 & 0.866 & 1 \\
\hline
\end{tabular}

$\mathrm{O}=\mathrm{IMP} \mid \mathrm{C}_{\mathrm{IMP}}=\{\mathrm{COM}, \mathrm{CHA}, \mathrm{AUT}, \mathrm{SOC}, \mathrm{MEA}\}$

meaningfulness as the degree to which individuals reconcile the purpose of their work and their own intentions and argues that it is closely related to intrinsic motivation. Also, self-determination theory implicitly acknowledges meaningfulness (Deci et al., 1994; Gagné \& Deci, 2005). It argues that intrinsically motivated individuals are more likely to internalize external regulation for those activities that they presume as personally meaningful (Gagné \& Deci, 2005) and draws parallels to the goal-setting theory that posits that meaningfulness at work supports the acceptance of imposed goals (Locke et al., 1988).

Table 3 summarizes the asf for impact as the second outcome factor (consistency threshold $=0.8$, coverage threshold $=0.85$ ). Accordingly, autonomy is necessary and sufficient for impact. This finding confirms the assumption by Ashforth (1990) that autonomy is a prerequisite for impact. Indeed, my data show that autonomy is the single prerequisite for impact.

Integrating the asf for intrinsic motivation as the outcome (Table 3) with the asf for impact as the outcome (Table 2) results in a common cause model in which both intrinsic motivation and impact are driven by autonomy (Table 4). In Boolean notation this structure can be summarized as $(\mathrm{AUT} \leftrightarrow \mathrm{IMP})^{*}(\mathrm{AUT}+\mathrm{MEA} \leftrightarrow \mathrm{INT})$. The model shows that there is a strong correlation between INT and IMP which, however, is not causal.

To summarize, the analysis of all causal factors proposed by the three motivation theories flow-theory, selfdetermination theory, and empowerment theory leads to a common cause model in which intrinsic motivation and impact correlate, but not causally (see Fig. 3). Both

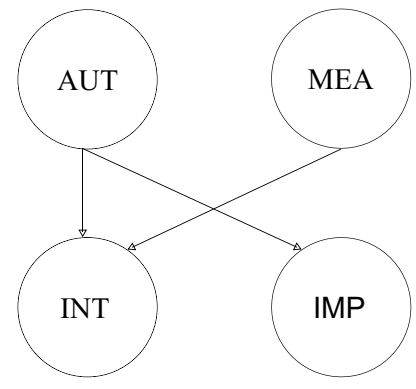

Fig. 3 Core model: common cause structure

outcomes are driven by autonomy. While high autonomy is sufficient and necessary for high impact, high levels of autonomy OR meaningfulness are sufficient and necessary for high intrinsic motivation, which means that one or the other factor can instantiate high intrinsic motivation and at least one of them must be present.

Obviously, there exists a discrepancy between the derived causal model and previous research. Although all three theories of intrinsic motivation contain competence as a causal factor for intrinsic motivation, the empirically derived model does not. Moreover, flow theory shows significant evidence for the interaction effects between competence and challenge, while the empirically derived model does not. Also, the empirically derived model does not contain social relatedness which is an integral part of self-determination theory. This means that relative to the consistency and coverage thresholds (consistency threshold $=0.8$, coverage threshold $=0.85$ ), there is no evidence in the dataset that either competence or social relatedness are difference-makers for intrinsic motivation. There are two possible explanations for this. First, competence and social relatedness may indeed be irrelevant for intrinsic motivation despite a substantial amount of previous research showing their relevance or, secondly, other difference-makers may overlay their effects. If the
Fig. 2 Sufficiency plot of AUT + MEA $\leftrightarrow$ INT

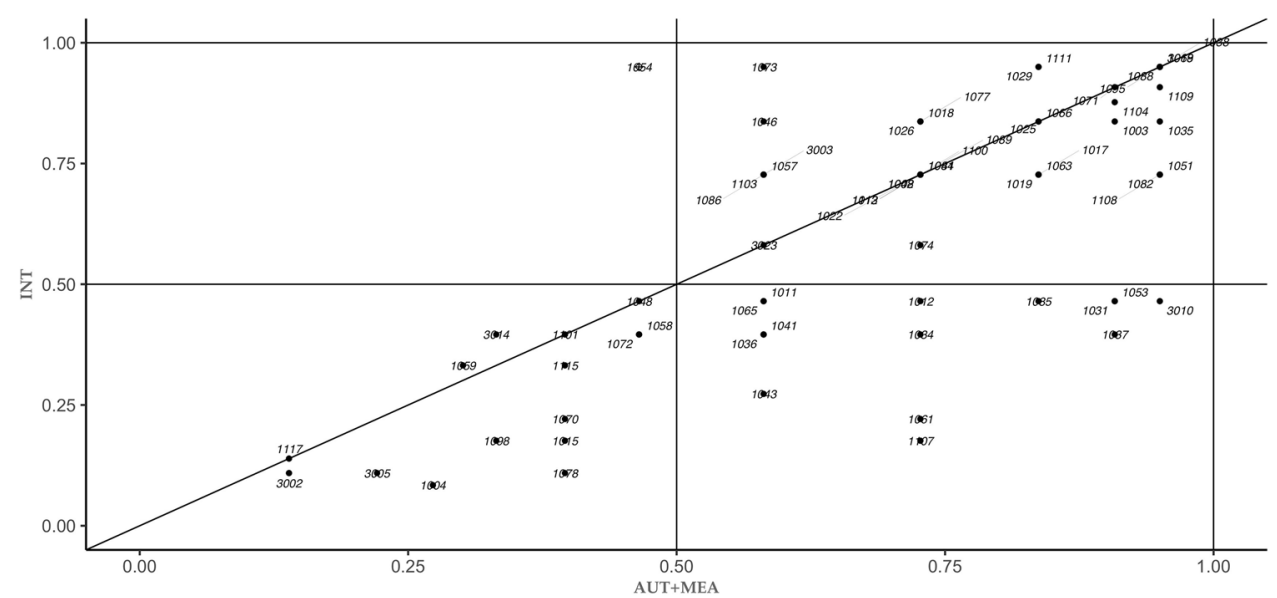


Table 4 CNA of complete model: csf

\begin{tabular}{llll}
\hline csf & Consistency & Coverage & Complexity \\
\hline$(\mathrm{AUT} \leftrightarrow \mathrm{IMP}) *(\mathrm{AUT}+\mathrm{MEA} \leftrightarrow \mathrm{INT})$ & 0.835 & 0.866 & 3 \\
\hline $\mathrm{O}=\{\mathrm{INT}, \mathrm{IMP}\}$ & $\mathrm{C}_{\mathrm{IMP}}=\{\mathrm{COM}, \mathrm{CHA}$, AUT, SOC, MEA $\}, \mathrm{C}_{\mathrm{INT}}=\{\mathrm{COM}, \mathrm{CHA}$, AUT, SOC, MEA, IMP $\}$
\end{tabular}

Table 5 CNA of flow theory factors: asf for INT

\begin{tabular}{llll}
\hline asf & Consistency & Coverage & Complexity \\
\hline $\mathrm{COM} \leftrightarrow \mathrm{INT}$ & 0.741 & 0.919 & 1 \\
\hline
\end{tabular}

$\mathrm{O}=\mathrm{INT} \mid \mathrm{C}_{\mathrm{INT}}=\{\mathrm{COM}, \mathrm{CHA}\}$

second option holds true, subsetting the dataset, which is performed in the next chapter, will shed light on the possible role of competence and social relatedness.

\section{Subsequent coincidence analyses from different theoretical lenses}

In order to examine the possible role of competence and social relatedness, in the following, the dataset will be subset according to the three theoretical perspectives. Although results will be lower or at the most equal in their model fit, subsetting will help to shed light on the potential roles of the remaining causal factors.

\section{Flow theory analysis}

In the "original" model, flow theory postulates that intrinsic motivation in a flow experience is felt when competence and challenge are in a balance while the "current" model of flow theory postulates that intrinsic motivation in a flow experience is felt when an individual perceives both high levels of competence and challenge (Csikszentmihalyi, 1975, 1990, 1997; Csikszentmihalyi \& LeFevre, 1989; Csikszentmihalyi et al., 2017; Nakamura \& Csikszentmihalyi, 2009). As both the "original" model and the "current" model make assumptions regarding the combinations of particular values for the two factors challenge and competence, both models could be revealed in my study design as CNA is explicitly designed to investigate interactions between several causal factors.

Table 5 summarizes the best fitting CNA model that includes only the two conditions COM and CHA and defines INT as the outcome (consistency threshold $=0.7$, coverage threshold $=0.85$ ). The consistency threshold was lowered to 0.7 , a threshold slightly below a reasonable value because no model reached higher consistency levels when only investigating the two causal factors, competence and challenge, proposed by flow theory.

Contrary to both the "original" and "current" postulates of the flow theory, the empirically derived model declares
Table 6 CNA of self-determination theory factors: asf for INT

\begin{tabular}{llll}
\hline asf & Consistency & Coverage & Complexity \\
\hline $\mathrm{AUT}+\mathrm{COM} * \mathrm{SOC} \leftrightarrow \mathrm{INT}$ & 0.818 & 0.867 & 3 \\
\hline
\end{tabular}

$\mathrm{O}=\mathrm{INT} \mid \mathrm{C}_{\mathrm{INT}}=\{\mathrm{COM}, \mathrm{AUT}, \mathrm{SOC}\}$

Table 7 CNA of empowerment theory factors: asf for INT

\begin{tabular}{llll}
\hline asf & Consistency & Coverage & Complexity \\
\hline AUT + MEA $\leftrightarrow$ INT & 0.840 & 0.945 & 2 \\
\hline
\end{tabular}

$\mathrm{O}=\mathrm{INT} \mid \mathrm{C}_{\mathrm{INT}}=\{\mathrm{COM}, \mathrm{AUT}, \mathrm{MEA}, \mathrm{IMP}\}$

that high competence on its own is, with the highest model fit, necessary and sufficient for high intrinsic motivation. However, with 0.741 , the consistency value is low pointing to an insufficient explanatory power of the two factors competence and challenges only. Despite this fact, my data still show that competence alone has a higher explanatory power than in any combination with challenge.

\section{Self-determination theory analysis}

Self-determination theory posits that the occurrence of the three causal factors competence, autonomy, and social relatedness is sufficient for high intrinsic motivation (Deci \& Ryan, 1985, 2000; Gagné \& Deci, 2005). In order to further examine the explanatory power of these three factors and especially competence and social relatedness as these two factors were not included in the core model (Fig. 3), subsetting is performed and a CNA conducted for intrinsic motivation as the outcome and the three causal factors postulated by self-determination theory: autonomy, competence, and social relatedness. Table 6 summarizes the best fitting CNA model from a self-determination theory perspective. In this case, a consistency score of 0.8 was still reached. Thus, 0.8 and 0.85 could be still used as the consistency and coverage thresholds.

Contrary to the propositions by self-determination theory, my data show for this subset of conditions that either high autonomy on its own or high competence in combination with high social relatedness is sufficient and their disjunction necessary for high intrinsic motivation. Thus, the results of the self-determination theory analysis may point to a different configuration of the same three factors as postulated by self-determination. The result with fairly high consistency 
Table 8 CNA of complete model: asf for MEA

\begin{tabular}{llll}
\hline asf & Consistency & Coverage & Complexity \\
\hline AUT + COM $*$ SOC $\leftrightarrow$ MEA & 0.815 & 0.862 & 3 \\
\hline $\mathrm{O}=$ MEA $\mid \mathrm{C}_{\mathrm{MEA}}=\{\mathrm{COM}, \mathrm{CHA}, \mathrm{AUT}, \mathrm{SOC}\}$
\end{tabular}

and coverage values points to causal roles of competence and social relatedness in preceding causal chains. This interpretation would also be in line with the causal role of competence that the flow theory analysis yielded in the last subchapter.

\section{Empowerment theory analysis}

Empowerment theory proposes the highest number of causal factors. It states that high competence, autonomy, impact, and meaningfulness lead to high empowerment as a state of intrinsic motivation (Conger \& Kanungo, 1988; Spreitzer, 1995). As the only of all three theories, it includes all causal factors revealed by the core model (Fig. 3). Thus, the results for the CNA conducted only for the empowerment theory factors (competence, autonomy, meaningfulness, impact), reveals the same model (Table 7) as the analysis of all potential causal factors from all three theories (Table 2). Also, the CNA on this subset could be accordingly performed for the same thresholds (consistency threshold $=0.8$, coverage threshold $=0.85$ ).

Again, the best fitting solution formula confirms that both high autonomy and meaningfulness are sufficient for high intrinsic motivation and their disjunction necessary. However, this model only contains two of the originally proposed four factors.

\section{Synopsis: tentative model}

Finally, a synopsis will bring the results of all preceding analyses together in a tentative model. The self-determination theory analysis showed that the factors competence and social relatedness may unfold relevance when subsetting the model and only analysing those factors that self-determination theory postulates as causally relevant. Accordingly, the flow theory analysis pointed to the relevance of competence when analysing only competence and challenge as causal factors for intrinsic motivation. Finally, empowerment theory evaluation strongly confirmed the disjunction of autonomy and meaningfulness as the most striking difference-makers for intrinsic motivation in the analysed dataset.

The only way to bring these insights together with the core model (Fig. 3) is when constructing a causal chain in which competence and social relatedness lead to meaningfulness. Thus, I conducted another CNA and ceteris paribus

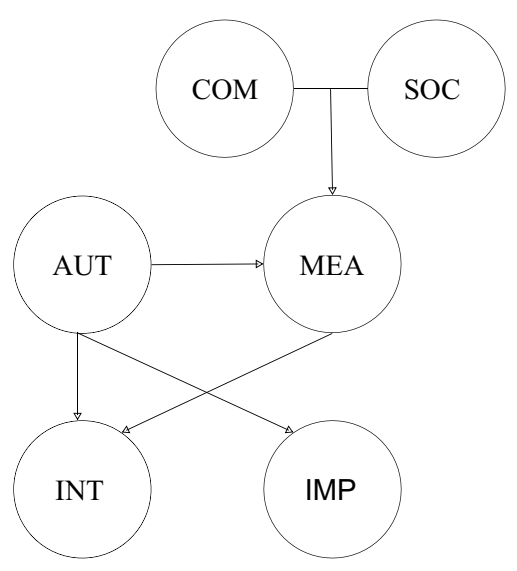

Fig. 4 Tentative model: common cause and causal chain structure

ordered meaningfulness as a third outcome before impact and intrinsic motivation. Table 8 shows the additional asf for meaningfulness as the outcome factor. The data show that high autonomy or the conjunction of high competence and high social relatedness lead to high meaningfulness.

This insight can be used to further develop the core model (Fig. 3) into the tentative model shown in Fig. 4.

The tentative model states that either high autonomy or high meaningfulness are sufficient for high intrinsic motivation and their disjunction necessary. Further, a common cause structure is described with impact as the second outcome that correlates with intrinsic motivation, but not causally. High autonomy is sufficient and necessary for high impact. In addition to these results that describe the core model (Fig. 3), the tentative model (Fig. 4) describes a causal chain with high competence together with high social relatedness or high autonomy being sufficient and their disjunction necessary for high meaningfulness.

Thus, a second common cause structure is revealed with high autonomy being sufficient for high meaningfulness, high impact, and high intrinsic motivation. In fact, as shown in Table 9, the derived complex solution formula with the highest model fit confirms the tentative model.

However, there are two major caveats concerning the tentative model. First, it is subject to high ambiguity in the data. Although the csf in Table 9 was chosen on the basis of substantive theory analysis, i.e. subsetting the dataset according to the three different theoretical lenses postulated by flow theory, self-determination theory, and empowerment theory, there exist ambiguous alternative explanations from the pure data analysis with only slightly lower fits. Second, and bearing in mind the first caveat, there is still higher evidence for the lower levels of the causal chain (nearer to the outcome) than for the higher levels (farther away from the outcome). Despite the two caveats, this model is still a tentative explanation that can solve the conflict between existing theories and the core model (Fig. 3) derived from the data. 
Table 9 CNA of complete model: csf

\begin{tabular}{llll}
\hline csf & Consistency & Coverage & Complexity \\
\hline$(\mathrm{AUT} \leftrightarrow \mathrm{IMP}) *(\mathrm{AUT}+\mathrm{MEA} \leftrightarrow \mathrm{INT}) *$ & 0.815 & 0.862 & 6 \\
$(\mathrm{AUT}+\mathrm{COM} * \mathrm{SOC} \leftrightarrow \mathrm{MEA})$ & & & \\
\hline
\end{tabular}

$\mathrm{O}=\{\mathrm{INT}, \mathrm{IMP}, \mathrm{MEA}\} \mid \mathrm{C}_{\mathrm{INT}}=\{\mathrm{COM}, \mathrm{CHA}, \mathrm{AUT}, \mathrm{SOC}, \mathrm{MEA}, \mathrm{IMP}\}, \mathrm{C}_{\mathrm{IMP}}=\{\mathrm{COM}, \mathrm{CHA}, \mathrm{AUT}, \mathrm{SOC}$, MEA $\}, \mathrm{C}_{\mathrm{MEA}}=\{\mathrm{COM}, \mathrm{CHA}, \mathrm{AUT}, \mathrm{SOC}\}$

\section{Discussion}

\section{Causal factors for intrinsic motivation}

Two results from this study are of major interest. The first is the major role that meaningfulness and autonomy play in the creation of intrinsic motivation. The second is the possible role of the remaining causal factors challenge, impact, and social relatedness.

Out of the six potential causal factors for intrinsic motivation, the analysed data show two to be causal for intrinsic motivation: autonomy and meaningfulness. More precisely, high autonomy or high meaningfulness are sufficient for high intrinsic motivation and one of them must be present (AUT + MEA $\leftrightarrow$ INT). This result supports the prominent role of autonomy in self-determination and empowerment theory and mirrors pivotal research on the importance of meaningfulness at work not only for general work motivation (Hackman \& Oldham, 1976), but also particularly for intrinsic motivation (Shamir, 1991). In fact, my data ascribe meaningfulness an even slightly more important role than autonomy as more cases are covered by meaningfulness ( 29 cases) than by autonomy ( 25 cases). In total, the solution formula (AUT + MEA $\leftrightarrow$ INT, Table 2, Fig. 2) covers 54 of all 55 cases that display high intrinsic motivation with only one outlier case (1054).

The core model (Fig. 3) shows that impact is not a causal factor for intrinsic motivation but rather a second outcome instantiated by a similar configuration of factors as intrinsic motivation. While high intrinsic motivation is instantiated by high autonomy or high meaningfulness (AUT + MEA $\leftrightarrow$ INT, Table 2, Fig. 2), high impact is instantiated by high autonomy only. Impact refers to the inner controllability of outcomes (Thomas \& Velthouse, 1990). The lack of impact is defined as learned helplessness (Martinko \& Gardner, 1982), ,the cognition that one lacks control over work outcomes" (Ashforth, 1989, p. 233). Thus, if autonomy is low, a lack of control is more probable.

The tentative model that I derived in my study (Fig. 4) also suggests a causal chain in which high autonomy or high competence in conjunction with high social relatedness are causal for high meaningfulness (AUT $+\mathrm{COM} * \mathrm{SOC} \leftrightarrow \mathrm{MEA}$, Table 8). Although tentative - as prone to high ambiguities in the data-, this model can be interpreted in line with previous research. A long tradition of meaning of work literature throughout many disciplines echoes the central role of meaningfulness in many work processes (Rosso et al., 2010). Further, the tentative model explicitly suggests that either high autonomy or high competence in conjunction with high social relatedness is sufficient for high meaningfulness and at least one of these disjuncts must be present. Interestingly, both disjuncts cover approximately the same number of analysed cases (AUT covers 19 cases while $\mathrm{COM} * \mathrm{SOC}$ covers 20 cases) and, thus, are equally important in the data set. A possible explanation for autonomy to be causal for meaningfulness is that only if individuals are free to choose their work actions, they can adjust them to their personal values and beliefs. The conjunction of high competence and high social relatedness can be explained through meaningfulness that is gained via encouragement and appreciation of other organizational members, e.g. colleagues or teamleaders. Usually, to be acknowledged for one's work, individuals need to feel competent in what they do. Thus, high competence in conjunction with high social relatedness, the state of having close relationships with other organizational members and to mutually appreciate one's work (Anderfuhren-Biget et al., 2010), could trigger seeing oneself as a highly valued expert, which in turn could serve as a source of meaningfulness. Interestingly, all three causal factors for meaningfulness from the tentative model correspond to the three basic human needs from self-determination theory (Deci \& Ryan, 1985, 2000; Gagné \& Deci, 2005). This could point to the explanation that in self-determination theory the fulfilment of the basic needs impacts intrinsic motivation through meaningfulness. Finally, given the set of analysed causal factors, my data do not show any evidence that challenge plays a causal role in the instantiation of intrinsic motivation.

\section{Implications for theory, research, and practice}

This study is the first that set out to investigate the foundations of intrinsic motivation from a configurational perspective. It is a first step to shed light on the complex, i.e. multi-causal, multi-outcome, and multi-level, configurations underlying the formation of intrinsic motivation. It also suggests that in addition to a single-theory perspective, research on intrinsic work motivation can benefit from a neo-configurational perspective that embraces various causal factors from multiple theoretical backgrounds. This perspective can 
serve diverse studies as a holistic framework to investigate particular drivers for intrinsic motivation, for example in research designs that investigate the question of how particular management tools can be designed to enhance intrinsic motivation.

Various insights can be gained from the results of this study. The analysis shows that the postulates of each theory of intrinsic motivation are individually too bold. Rather than being sufficient and necessary on their own, different conditions from several theories interplay on multiple levels. My results show that perceiving either high meaningfulness or high autonomy at work is a difference-maker for high intrinsic motivation. Moreover, impact was not shown to be causal for intrinsic motivation but rather a second outcome driven by similar factors as intrinsic motivation. Further indepth analyses through the lenses of particular motivation theories suggest a tentative model in order to resolve tensions between theoretical postulates and empirical evidence.

By overcoming the limitations of cross-sectional designs and commonly used statistical analyses, the study proposes that there exists no straightforward explanation for intrinsic motivation, but rather complex multi-outcome configurations instantiate intrinsic motivation. In doing so, it answers Rosso et al.'s (2010) call for more research methods capable of disentangling the potential interactive effects of intrinsic motivation and meaningfulness and encourages researchers to think configurationally. Further, my results demonstrate the promise of a person-centered approach to configurational comparative research for advancing motivation research and management development.

From a practical viewpoint, the study has clear managerial implications. It provides fine-grained guidance on how to enhance intrinsic motivation in organizations and proposes to primarily consider autonomy and meaningfulness as resource-efficient levers when designing intrinsically motivating job contexts. Secondary, and tentatively, in order to provide for high meaningfulness at work, competence and social relatedness may be adressed.

\section{Limitations and future directions}

The study is not without limitations. First, it was conducted in the specific context of a German public utility. However, for conducting a CNA, and to overcome limitations of crosssectional studies, it is crucial to provide for homogeneity, i.e. to hold other possible causal factors than the investigated as equal as possible (Baumgartner \& Ambühl, 2020a; BergSchlosser \& De Meur, 2009). This is a prerequisite for inferring to causation via cross-case comparisons (Baumgartner, 2009). Therefore, I have chosen to conduct the study in one organisation. However, future research is needed to explore the neo-configurational theory of intrinsic motivation in different settings and the related contingencies for further theory development and refinement.

Second, like in most cross-case studies, I could not provide for perfect diversity. Some configurations could simply not be observed. Most importantly, the factor competence shows the highest skewness in the data and, thus, the interpretation of results regarding competence is most limited. Further, I designed the study in order to maximize homogeneity. However, as in all settings, not all possible causal factors can be guaranteed to be constant. Thus, the causal relations in this study hold true for similar settings only. Subsequent research is needed to challenge my findings in different settings.

Third, as all investigated theories refer to perceptions of all investigated factors, I collected data on an individual level via an online survey drawing on multiply validated scales mainly from the realm of self-determination theory and empowerment theory (Ashforth, 1989; Gagné et al., 2015; Spreitzer, 1995; Van den Broeck et al., 2010). Although thoroughly developed, the data collection differs from the measurements used in research in the tradition of flow theory. Flow theory uses individually computed averages of respondents to determine the values of perceived challenges and competences (Csikszentmihalyi \& LeFevre, 1989; Csikszentmihalyi et al., 2014). However, in order to align the data collection processes throughout all theories, I did not use this method for my data collection.

In addition, future research may wish to add the frustrations of the investigated needs (Vansteenkiste \& Ryan, 2013; Warburton et al., 2020) as additional factors, add new factors, for example new candidate needs that recent basic psychological needs theory research proposes (Baxter \& Pelletier, 2019; González-Cutre et al., 2020; Martela \& Ryan, 2016; Prentice et al., 2020), or investigate, in addition to intrinsic motivation, also other types of motivations, profiles thereof (Howard et al., 2016, 2020a, 2020b), or overall motivation scores (Howard, et al., 2020a, 2020b) as outcome factors. Moreover, flow theory also proposes further, more distal causal factors like clear goals and immediate feedback that may shed light on additional causal chains and add further causal layers to forthcoming investigations. Last but not least, follow-up case studies could be performed especially on outlier cases (e.g. case 1054) in order to shed light on those causal factors that were possibly overlooked by all three theories of intrinsic motivation.

\section{Conclusion}

This study set out to investigate the highly complex causal structure behind the formation of intrinsic motivation at work. The obtained core model reveals high 
meaningfulness and high autonomy as two sufficient factors for high intrinsic motivation and their disjunction as necessary, i.e. either high meaningfulness or high autonomy lead to intrinsic motivation ("are sufficient") and at least one of these factors must be present to provide for high intrinsic motivation ("is necessary"). By analysing different existing motivation theories further, my analyses reveal a tentative causal chain structure in which either high autonomy or high competence in conjunction with high social relatedness can lead to high meaningfulness at work ("are sufficient") and at least one of these disjuncts must be present to provide for high meaningfulness ("is necessary"). However, the tentative model is not without caveats as it is subject to relatively high ambiguity in the dataset. Further, I shed light on the role of impact. Surprisingly, impact was not shown to be a causal factor for intrinsic motivation, but the data rather reveal a common cause in which impact is driven by autonomy solely ("is sufficient and necessary"). Breaking up the causal complexity behind the formation of intrinsic motivation this research is the first to demonstrate alternative paths and multi-outcome structures towards intrinsic motivation at work.

\section{Appendix}

See Table 10.
Table 10 Outcomes and causal factors: items

\begin{tabular}{|c|c|c|c|c|}
\hline Set & & & Item & Loading \\
\hline \multirow{4}{*}{$\begin{array}{l}\text { Intrinsic motivation } \\
A V E: 0.791\end{array}$} & \multirow{4}{*}{ INT } & & I put efforts into my job... & \\
\hline & & INT1 & ...because I have fun doing my job & 1.006 \\
\hline & & INT2 & ...because what I do in my work is exciting & 1.071 \\
\hline & & INT3 & ...because the work I do is interesting & 1.084 \\
\hline \multirow{4}{*}{$\begin{array}{l}\text { Impact } \\
A V E: 0.603\end{array}$} & \multirow[t]{4}{*}{ IMP } & IMP1 & I have an impact on what happens at work & 0.979 \\
\hline & & IMP2 & I have control over what happens at my work & 0.987 \\
\hline & & IMP3 & I can change things at work & 1.049 \\
\hline & & IMP5 & I can actively influence my work results & 0.884 \\
\hline \multirow{3}{*}{$\begin{array}{l}\text { Competence } \\
A V E: 0.626\end{array}$} & \multirow[t]{3}{*}{$\mathrm{COM}$} & COM1 & I am self-assured about my capability to do my work & 0.586 \\
\hline & & COM2 & I have mastered the skills necessary for my job & 0.883 \\
\hline & & COM3 & I am good at the things I do in my job & 0.429 \\
\hline \multirow{2}{*}{$\begin{array}{l}\text { Challenge } \\
A V E: 0.603\end{array}$} & \multirow[t]{2}{*}{ CHA } & CHA1 & My work activities are challenging & 0.935 \\
\hline & & CHA3 & My work demands too little from me. (R) & 0.938 \\
\hline \multirow{3}{*}{$\begin{array}{l}\text { Autonomy } \\
A V E: 0.612\end{array}$} & \multirow[t]{3}{*}{ AUT } & AUT1 & I can decide on my own how to go about doing my work & 0.839 \\
\hline & & AUT3 & $\begin{array}{l}\text { The tasks I have to do at work are in line with what I } \\
\text { really want to do }\end{array}$ & 1.049 \\
\hline & & AUT4 & I feel like I can be myself at my job & 1.129 \\
\hline \multirow{2}{*}{$\begin{array}{l}\text { Social relatedness } \\
A V E: 0.702\end{array}$} & \multirow[t]{2}{*}{ SOC } & SOC1 & At work, I feel part of a group & 0.965 \\
\hline & & SOC2 & At work, I connect with others & 0.965 \\
\hline \multirow{3}{*}{$\begin{array}{l}\text { Meaningfulness } \\
A V E: 0.585\end{array}$} & \multirow[t]{3}{*}{ MEA } & MEA1 & The work I do is important to me & 0.759 \\
\hline & & MEA2 & My job activities are personally meaningful to me & 0.973 \\
\hline & & MEA3 & The work I do is meaningful & 0.881 \\
\hline
\end{tabular}

Model fit: $\mathrm{CFI}=0.942, \mathrm{TLI}=0.928, \mathrm{RMSEA}=0.062, \mathrm{SRMR}=0.076$ 
Supplementary Information The online version contains supplementary material available at https://doi.org/10.1007/s11031-021-09906-1.

Acknowledgements I thank all the participants in my survey as well as the investigated public utility's CEO and Human Resource Manager for their great support of my research. I also thank Michael Baumgartner for his much-appreciated comments on previous versions of the paper and I thank the CCM community for valuable inputs at two different QCA workshops.

Funding Open access funding was provided by University of Bergen (incl Haukeland University Hospital). I gratefully acknowledge the support by the Toppforsk program of the University of Bergen, co-financed by the Trond Mohn Foundation (Grant No. 811886).

\section{Declarations}

Conflict of interest The author declares that she has no conflict of interest.

Ethical approval All procedures performed in studies involving human participants were in accordance with the ethical standards of the institutional and/or national research committee and with the 1964 Helsinki declaration and its later amendments or comparable ethical standards.

Informed consent Informed consent was obtained from all individual participants in the survey.

Open Access This article is licensed under a Creative Commons Attribution 4.0 International License, which permits use, sharing, adaptation, distribution and reproduction in any medium or format, as long as you give appropriate credit to the original author(s) and the source, provide a link to the Creative Commons licence, and indicate if changes were made. The images or other third party material in this article are included in the article's Creative Commons licence, unless indicated otherwise in a credit line to the material. If material is not included in the article's Creative Commons licence and your intended use is not permitted by statutory regulation or exceeds the permitted use, you will need to obtain permission directly from the copyright holder. To view a copy of this licence, visit http://creativecommons.org/licenses/by/4.0/.

\section{References}

Alderfer, C. P. (1972). Existence, relatedness, and growth. Free Press. Amabile, T. M. (1985). Motivation and creativity: Effects of motivational orientation on creative writers. Journal of Personality and Social Psychology, 48(2), 393-399.

Amabile, T. M. (1988). A model of creativity and innovation in organizations. Research in Organizational Behavior, 10, 123-167.

Amabile, T. M., DeJong, W., \& Lepper, M. R. (1976). Effects of externally imposed deadlines on subsequent intrinsic motivation. Journal of Personality and Social Psychology, 34(1), 92-98. https://doi.org/10.1037/0022-3514.34.1.92

Anderfuhren-Biget, S., Varone, F., Giauque, D., \& Ritz, A. (2010). Motivating employees of the public sector: Does public service motivation matter? International Public Management Journal, 13(3), 213-246. https://doi.org/10.1080/10967494.2010.503783

Andreassen, C. S., Hetland, J., \& Pallesen, S. (2010). The Relationship Between 'Workaholism', Basic Needs Satisfaction at Work and Personality. European Journal of Personality, 24, 3-17.
Arel-Bundock, V. (2019). The double bind of qualitative comparative analysis. Sociological Methods and Research. https://doi.org/ 10.1177/0049124119882460

Ashforth, B. E. (1989). The experience of powerlessness in organizations. Organizational Behavior and Human Decision Processes, 43(2), 207-242. https://doi.org/10.1016/0749-5978(89) 90051-4

Ashforth, B. E. (1990). The organizationally induced helplessness syndrome: A preliminary model. Canadian Journal of Administrative Sciences / Revue Canadienne Des Sciences De L'administration, 7(3), 30-36. https://doi.org/10.1111/j.19364490.1990.tb00532.x

Atkinson, J. W. (1964). An introduction to motivation. Van Nostrand.

Bakker, A. B. (2008). The work-related flow inventory: Construction and initial validation of the WOLF. Journal of Vocational Behavior, 72(3), 400-414. https://doi.org/10.1016/j.jvb.2007.11.007

Baumeister, R. F., \& Leary, M. R. (1995). The need to belong: Desire for interpersonal attachments as a fundamental human motivation. Psychological Bulletin, 117(3), 497-529. https://doi.org/10. 1037//0033-2909.117.3.497

Baumgartner, M. (2009). Inferring causal complexity. Sociological Methods and Research, 38(1), 71-101.

Baumgartner, M. (2015). Parsimony and causality. Quality and Quantity, 49(2), 839-856.

Baumgartner, M., \& Ambühl, M. (2020a). Causal modeling with multi-value and fuzzy-set Coincidence Analysis. Political Science Research and Methods, 8(3), 526-542.

Baumgartner, M., \& Ambühl, M. (2020b). cna: An R Package for Configurational Causal Inference and Modeling. https://cran.r-proje ct.org/web/packages/cna/vignettes/cna.pdf

Baumgartner, M., \& Falk, C. (2019). Boolean difference-making: A modern regularity theory of causation. The British Journal for the Philosophy of Science. https://doi.org/10.1093/bjps/axz047

Baumgartner, M., \& Thiem, A. (2015). Identifying complex causal dependencies in configurational data with coincidence analysis. R Journal, 7(1), 176-184.

Baxter, D. E., \& Pelletier, L. G. (2019). Is nature relatedness a basic human psychological need? A critical examination of the extant literature. Canadian Psychology, 60(1), 21-34. https://doi.org/ 10.1037/cap0000145

Berg-Schlosser, D., \& De Meur, G. (2009). Comparative research design: Case and variable selection. In B. Rihoux \& C. C. Ragin (Eds.), Configurational comparative methods: Qualitative comparative analysis (QCA) and related techniques (pp. 19-32). Sage Publications.

Berg-Schlosser, D., De Meur, G., Rihoux, B., \& Ragin, C. C. (2009). Qualitative comparative analysis (QCA) as an approach. In B. Rihoux \& C. C. Ragin (Eds.), Configurational comparative methods: qualitative comparative analysis $(Q C A)$ and related techniques (pp. 1-32). Sage Publications.

Boggiano, A. K., \& Ruble, D. N. (1979). Competence and the overjustification effect: A developmental study. Journal of Personality and Social Psychology, 37(9), 1462-1468. https://doi.org/10. 1037/0022-3514.37.9.1462

Burks, S., Carpenter, J., \& Goette, L. (2009). Performance pay and worker cooperation: Evidence from an artefactual field experiment. Journal of Economic Behavior and Organization, 70(3), 458-469. https://doi.org/10.1016/j.jebo.2008.02.012

Cellar, D. F., \& Barrett, G. V. (1987). Script processing and intrinsic motivation: The cognitive sets underlying cognitive labels. Organizational Behavior and Human Decision Processes, 40(1), 115-135. https://doi.org/10.1016/0749-5978(87)90008-2

Chang, G. S. Y., \& Lorenzi, P. (1983). The effects of participative versus assigned goal setting on intrinsic motivation. Journal of Management, 9(1), 55-64. https://doi.org/10.1177/0149206383 00900106 
Chen, H., Wigand, R. T., \& Nilan, M. S. (1999). Optimal experience of Web activities. Computers in Human Behavior, 15(5), 585-608. https://doi.org/10.1016/S0747-5632(99)00038-2

Conger, J. A., \& Kanungo, R. N. (1988). The empowerment process: Integrating theory and practice. Academy of Management Review, 13(3), 471-482. https://doi.org/10.5465/amr.1988.4306983

Csikszentmihalyi, M. (1975). Beyond boredom and anxiety. JosseyBass Publishers.

Csikszentmihalyi, M. (1990). Flow : The psychology of optimal experience. Harper \& Row.

Csikszentmihalyi, M. (1997). Finding flow : The psychology of engagement with everyday life. Basic Books.

Csikszentmihalyi, M. (1999). If we are so rich, why aren't we happy? American Psychologist, 54(10), 821-827. https://doi.org/10. 1037/0003-066x.54.10.821

Csikszentmihalyi, M. (2014). Toward a psychology of optimal experience. In M. Csikszentmihalyi (Ed.), Flow and the foundations of positive psychology: The collected works of Mihaly Csikszentmihalyi (pp. 209-226). Springer. https://doi.org/10.1007/ 978-94-017-9088-8

Csikszentmihalyi, M., Graef, R., \& McManama Gianinno, S. (2014). Measuring intrinsic motivation in everyday life. In M. Csikszentmihalyi, R. Graef, \& S. McManama Gianinno (Eds.), Flow and the foundations of positive psychology: The collected works of Mihaly Csikszentmihalyi (pp. 113-125). Springer. https://doi. org/10.1007/978-94-017-9088-8

Csikszentmihalyi, M., \& LeFevre, J. (1989). Optimal experience in work and leisure. Journal of Personality and Social Psychology, 56(5), 815-822. https://doi.org/10.1037//0022-3514.56.5.815

Csikszentmihalyi, M., Montijo, M. N., \& Mouton, A. R. (2017). Flow theory: Optimizing elite performance in the creative realm. APA Handbook of Giftedness and Talent. https://doi.org/10.1037/ 0000038-014

Csikszentmihalyi, M., Rathunde, K., \& Whalen, S. (1997). Talented teenagers: The roots of success and failure. Cambridge University Press.

De Cooman, R., Stynen, D., Van den Broeck, A., Sels, L., \& De Witte, H. (2013). How job characteristics relate to need satisfaction and autonomous motivation: Implications for work effort. Journal of Applied Social Psychology, 43(6), 1342-1352. https://doi.org/ 10.1111/jasp. 12143

Deci, E. L. (1971). Effects of externally mediated rewards on intrinsic motivation. Journal of Personality and Social Psychology, 18(1), 105-115. https://doi.org/10.1037/h0030644

Deci, E. L., Connell, J. P., \& Ryan, R. M. (1989). Self-determination in a work organization. Journal of Applied Psychology, 74(4), 580-590. https://doi.org/10.1037/0021-9010.74.4.580

Deci, E. L., Eghrarl, H., Patrick, B. C., \& Leone, D. R. (1994). Facilitating Internallzatlon: The Self-Determinatlon Theory Perspective. Journal of Personality, 62(1), 119-142. https://doi.org/10. 1111/j.1467-6494.1994.tb00797.x

Deci, E. L., \& Ryan, R. M. (1985). Intrinsic motivation and self-determination in human behavior. In E. L. Deci \& R. M. Ryan (Eds.), Intrinsic motivation and self-determination in human behavior. Plenum. https://doi.org/10.1007/978-1-4899-2271-7

Deci, E. L., \& Ryan, R. M. (2000). The "what" and "why" of goal pursuits: Human needs and the self-determination of behavior. Psychological Inquiry, 11(4), 227-268. https://doi.org/10.1207/ S15327965PLI1104_01

Delle Fave, A., Massimini, F., \& Bassi, M. (2011). Psychological selection and optimal experience across cultures: Social empowerment through personal growth. Springer.

Demerouti, E. (2006). Job characteristics, flow, and performance: The moderating role of conscientiousness. Journal of Occupational Health Psychology, 11(3), 266-280. https://doi.org/10.1037/ 1076-8998.11.3.266
Drake, A. R., Wong, J., \& Salter, S. B. (2007). Empowerment, motivation, and performance: Examining the impact of feedback and incentives on nonmanagement employees. Behavioral Research in Accounting, 19(1), 71-89. https://doi.org/10.2308/bria.2007. 19.1.71

Duşa, A. (2019). QCA with R: A comprehensive resource. Springer.

Eisenberger, R., Jones, J. R., Stinglhamber, F., Shanock, L., \& Randall, A. T. (2005). Flow experiences at work: For high need achievers alone? Journal of Organizational Behavior, 26(7), 755-775. https://doi.org/10.1002/job.337

Engeser, S., \& Baumann, N. (2016). Fluctuation of flow and affect in everyday life: A second look at the paradox of work. Journal of Happiness Studies, 17(1), 105-124. https://doi.org/10.1007/ s10902-014-9586-4

Fong, C. J., Zaleski, D. J., \& Leach, J. K. (2015). The challenge-skill balance and antecedents of flow: A meta-analytic investigation. Journal of Positive Psychology, 10(5), 425-446. https://doi.org/ 10.1080/17439760.2014.967799

Fornell, C., \& Larcker, D. F. (1981). Evaluating structural equation models with unobservable variables and measurement error. Journal of Marketing Research, 18(1), 39. https://doi.org/10. 2307/3151312

Frankl, V. E. (1959). Man's search for meaning. Beacon Press.

Freedman, S. M., \& Phillips, J. S. (1985). The effects of situational performance constraints on intrinsic motivation and satisfaction: The role of perceived competence and self-determination. Organizational Behavior and Human Decision Processes, 35(3), 397-416. https://doi.org/10.1016/0749-5978(85)90030-5

Fullagar, C. J., \& Kelloway, E. K. (2009). "Flow" at work: An experience sampling approach. Journal of Occupational and Organizational Psychology, 82(3), 595-615. https://doi.org/10.1348/ 096317908X357903

Furnari, S., Crilly, D., Misangyi, V. F., Greckhamer, T., Aguilera, R., \& Fiss, P. C. (2020). Capturing causal complexity: A configurational theorizing process. Academy of Management Review. https://doi.org/10.5465/amr.2019.0298

Furr, M. R. (2011). Scale construction and psychometrics for social and personality psychology. Sage Publications.

Gabriel, A. S., Campbell, J. T., Djurdjevic, E., Johnson, R. E., \& Rosen, C. C. (2018). Fuzzy profiles: Comparing and contrasting latent profile analysis and fuzzy set qualitative comparative analysis for person-centered research. Organizational Research Methods, 21(4), 877-904. https://doi.org/10.1177/1094428117752466

Gagné, M. (2003). The role of autonomy support and autonomy orientation in prosocial behavior engagement. Motivation and Emotion, 27(3), 199-223. https://doi.org/10.1023/A:1025007614869

Gagné, M. (2009). A model of knowledge-sharing motivation. Human Resource Management, 48(4), 571-589. https://doi.org/10.1002/ hrm. 20298

Gagné, M., \& Deci, E. L. (2005). Self-determination theory and work motivation. Journal of Organizational Behavior, 26, 331-362.

Gagné, M., Forest, J., Vansteenkiste, M., Crevier-Braud, L., Van den Broeck, A., Aspeli, A. K., Bellerose, J., Benabou, C., Chemolli, E., Güntert, S. T., Halvari, H., Indiyastuti, D. L., Johnson, P. A., Molstad, M. H., Naudin, M., Ndao, A., Olafsen, A. H., Roussel, P., Wang, Z., \& Westbye, C. (2015). The Multidimensional Work Motivation Scale: Validation evidence in seven languages and nine countries. European Journal of Work and Organizational Psychology, 24(2), 178-196. https://doi.org/10.1080/1359432X. 2013.877892

Gagné, M., Tian, A. W., Soo, C., Zhang, B., Ho, K. S. B., \& Hosszu, K. (2019). Different motivations for knowledge sharing and hiding: The role of motivating work design. Journal of Organizational Behavior, 40(7), 783-799. https://doi.org/10.1002/job. 2364 
Gist, M. E. (1987). Self-efficacy: Implications for organizational behavior and human resource management. Academy of Management Review, 12(3), 472-485. https://doi.org/10.5465/amr.1987.43065 62

Glaesser, J., \& Cooper, B. (2014). Exploring the consequences of a recalibration of causal conditions when assessing sufficiency with fuzzy set QCA. International Journal of Social Research Methodology, 17(4), 387-401. https://doi.org/10.1080/13645579. 2013.769782

Goertz, G. (2006). Social Science Concepts. Princeton University Press.

González-Cutre, D., Romero-Elías, M., Jiménez-Loaisa, A., BeltránCarrillo, V. J., \& Hagger, M. S. (2020). Testing the need for novelty as a candidate need in basic psychological needs theory. Motivation and Emotion, 44(2), 295-314. https://doi.org/10. 1007/s11031-019-09812-7

Grant, A. M. (2008a). Does intrinsic motivation fuel the prosocial fire? Motivational synergy in predicting persistence, performance, and productivity. Journal of Applied Psychology, 93(1), 48-58. https://doi.org/10.1037/0021-9010.93.1.48

Grant, A. M. (2008b). The significance of task significance: Job performance effects, relational mechanisms, and boundary conditions. Journal of Applied Psychology, 93(1), 108-124. https://doi.org/ 10.1037/0021-9010.93.1.108

Graves, L. M., Cullen, K. L., Lester, H. F., Ruderman, M. N., \& Gentry, W. A. (2015). Managerial motivational profiles: Composition, antecedents, and consequences. Journal of Vocational Behavior, 87, 32-42. https://doi.org/10.1016/j.jvb.2014.12.002

Hackman, J. R., \& Oldham, G. R. (1975). Development of the job diagnostic survey. Journal of Applied Psychology, 60, 59-170.

Hackman, J. R., \& Oldham, G. R. (1976). Motivation through the design of work: Test of a theory. Organizational Behavior and Human Performance, 16(21), 250-279. https://doi.org/10.1016/ 0030-5073(76)90016-7

Haesebrouck, T. (2019). Who follows whom? A coincidence analysis of military action, public opinion and threats. Journal of Peace Research, 56(6), 753-766. https://doi.org/10.1177/0022343319 854787

Herzberg, F. (1966). Work and the nature of man. World Publishing.

Hom, H. L., \& Maxwell, F. R. (1983). The impact of task difficulty expectations on intrinsic motivation. Motivation and Emotion, 7(1), 19-24. https://doi.org/10.1007/BF00992962

Howard, J. L., Gagné, M., Morin, A. J. S., \& Van den Broeck, A. (2016). Motivation profiles at work: A self-determination theory approach. Journal of Vocational Behavior, 95-96, 74-89. https:// doi.org/10.1016/j.jvb.2016.07.004

Howard, J. L., Gagné, M., Van den Broeck, A., Guay, F., Chatzisarantis, N., Ntoumanis, N., \& Pelletier, L. G. (2020a). A review and empirical comparison of motivation scoring methods: An application to self-determination theory. Motivation and Emotion, 44(4), 534-548. https://doi.org/10.1007/s11031-020-09831-9

Howard, J. L., Morin, A. J. S., \& Gagné, M. (2020b). A longitudinal analysis of motivation profiles at work. Motivation and Emotion. https://doi.org/10.1007/s11031-020-09852-4

Jaworski, B. J., \& Young, S. M. (1992). Dysfunctional behavior and management control: An empirical study of marketing managers. Accounting, Organizations and Society, 17(1), 17-35. https://doi. org/10.1016/0361-3682(92)90034-P

Keller, J., \& Bless, H. (2008). Flow and regulatory compatibility: An experimental approach to the flow model of intrinsic motivation. Personality and Social Psychology Bulletin, 34(2), 196-209. https://doi.org/10.1177/0146167207310026

Keller, J., Ringelhan, S., \& Blomann, F. (2011). Does skills-demands compatibility result in intrinsic motivation? experimental test of a basic notion proposed in the theory of flow-experiences.
Journal of Positive Psychology, 6(5), 408-417. https://doi.org/ 10.1080/17439760.2011.604041

Kowal, J., \& Fortier, M. S. (1999). Motivational determinants of flow: Contributions from self-determination theory. Journal of Social Psychology, 139(3), 355-368. https://doi.org/10.1080/00224 549909598391

Kruglanski, A. W. (1978). Endogenous attribution and intrinsic motivation. In M. Lepper \& D. Greene (Eds.), The hidden costs of reward: New perspectives on the psychology of human motivation (pp. 85-107). Erlbaum.

Langevin, P., \& Mendoza, C. (2013). How can management control system fairness reduce managers' unethical behaviours? European Management Journal, 31(3), 209-222. https://doi.org/10. 1016/j.emj.2012.12.001

Lenzner, T., Neuert, C., \& Otto, W. (2016). Cognitive pretesting. In GESIS Survey Guidelines (Version 2.0).

Lindsley, D. H., Brass, D. J., \& Thomas, J. B. (1995). Efficacy-Performance Spirals: A Multilevel Perspective. Academy of Management Review, 20(3), 645. https://doi.org/10.2307/258790

Locke, E. A., \& Latham, G. P. (1990). A theory of goal setting and task performance. Prentice Hall.

Locke, E. A., Latham, G. P., \& Erez, M. (1988). The determinants of goal commitment. Academy of Management Review, 13(1), 23-39. https://doi.org/10.5465/AMR.1988.4306771

Mackie, J. L. (1974). The Cement of the Universe: A Study of Causation. Clarendon Press.

Mahoney, J. (2008). Toward a unified theory of causality. Comparative Political Studies, 41(4-5), 412-436.

Malik, M. A. R., Choi, J. N., \& Butt, A. N. (2019). Distinct effects of intrinsic motivation and extrinsic rewards on radical and incremental creativity: The moderating role of goal orientations. Journal of Organizational Behavior, 40(9-10), 1013-1026. https:// doi.org/10.1002/job.2403

Martela, F., \& Ryan, R. M. (2016). The benefits of benevolence: Basic psychological needs, beneficence, and the enhancement of wellbeing. Journal of Personality, 84(6), 750-764. https://doi.org/ 10.1111/jopy. 12215

Martinko, M. J., \& Gardner, W. L. (1982). Learned helplessness: An alternative explanation for performance deficits. Academy of Management Review, 7(2), 195-204. https://doi.org/10.5465/ amr.1982.4285559

Maslow, A. H. (1954). Motivation and personality. Harper \& Row.

Maslow, A. H. (1971). The farther reaches of human nature. The Viking Press.

McGraw, K. O., \& McCullers, J. C. (1979). Evidence of a detrimental effect of extrinsic incentives on breaking a mental set. Journal of Experimental Social Psychology, 15(3), 285-294. https://doi. org/10.1016/0022-1031(79)90039-8

McGregor, D. (1960). The human side of enterprise. McGraw-Hill.

Misangyi, V. F., Greckhamer, T., Furnari, S., Fiss, P. C., Crilly, D., \& Aguilera, R. (2016). Embracing causal complexity: The emergence of a neo-configurational perspective. Journal of Management, 43(1), 255-282.

Moneta, G. B. (2012). Opportunity for creativity in the job as a moderator of the relation between trait intrinsic motivation and flow in work. Motivation and Emotion, 36(4), 491-503. https://doi. org/10.1007/s11031-012-9278-5

Moneta, G. B., \& Csikszentmihalyi, M. (1999). Models of concentration in natural environments: A comparative approach based on streams of experiential data. Social Behavior and Personality, 27(6), 603-638. https://doi.org/10.2224/sbp.1999.27.6.603

Moran, C. M., Diefendorff, J. M., Kim, T. Y., \& Liu, Z. Q. (2012). A profile approach to self-determination theory motivations at work. Journal of Vocational Behavior, 81(3), 354-363. https:// doi.org/10.1016/j.jvb.2012.09.002 
Mossholder, K. W. (1980). Effects of externally mediated goal setting on intrinsic motivation: A laboratory experiment. Journal of Applied Psychology, 65(2), 202-210. https://doi.org/10.1037// 0021-9010.65.2.202

Nakamura, J., \& Csikszentmihalyi, M. (2009). Flow theory and research. In S. J. Lopez \& C. R. Snyder (Eds.), Oxford handbook of positive psychology (2nd ed., pp. 195-206). Oxford University Press.

Nielsen, J. D., Thompson, J. A., Wadsworth, L. L., \& Vallett, J. D. (2020). The moderating role of calling in the work-family interface: Buffering and substitution effects on satisfaction. Journal of Organizational Behavior. https://doi.org/10.1002/job.2469

Oana, I.-E., \& Schneider, C. Q. (2018). SetMethods: An add-on R package for advanced QCA. $R$ Journal, 10(1), 507-533. https:// doi.org/10.32614/rj-2018-031

Oana, I.-E., Schneider, C. Q., \& Thomann, E. (2021). Qualitative comparative analysis (QCA) using $R$ : A beginner's guide. Cambridge University Press.

Olafsen, A. H., Halvari, H., Forest, J., \& Deci, E. L. (2015). Show them the money? The role of pay, managerial need support, and justice in a self-determination theory model of intrinsic work motivation. Scandinavian Journal of Psychology, 56(4), 447-457. https://doi.org/10.1111/sjop.12211

Parkkinen, V.-P., \& Baumgartner, M. (2021). Robustness and model selection in configurational causal modeling. Sociological Methods \& Research. https://doi.org/10.1177/0049124120986200

Prentice, M., Jayawickreme, E., \& Fleeson, W. (2020). An experience sampling study of the momentary dynamics of moral, autonomous, competent, and related need satisfactions, moral enactments, and psychological thriving. Motivation and Emotion, 44(2), 244-256. https://doi.org/10.1007/s11031-020-09829-3

Ragin, C. C. (1987). The comparative method: Moving beyond qualitative and quantitative strategies. University of California Press.

Ragin, C. C. (2000). Fuzzy-set social science. University of Chicago Press.

Ragin, C. C. (2008). Redisigning social inquiry: Fuzzy sets and beyond. University of Chicago Press.

Richer, S. F., Blanchard, C., \& Vallerand, R. J. (2002). A motivational model of work turnover. Journal of Applied Social Psychology, 32(10), 2089-2113. https://doi.org/10.1111/j.1559-1816.2002. tb02065.x

Rihoux, B., \& Ragin, C. C. (2009). Configurational comparative methods: Qualitative comparative analysis $(Q C A)$ and related techniques. Sage Publications.

Rogers, C. R. (1961). On becoming a person. Houghton Mifflin.

Rosso, B. D., Dekas, K. H., \& Wrzesniewski, A. (2010). On the meaning of work: A theoretical integration and review. Research in Organizational Behavior, 30, 91-127. https://doi.org/10.1016/j. riob.2010.09.001

Ryan, R. M. (1982). Control and information in the intrapersonal sphere: An extension of cognitive evaluation theory. Journal of Personality and Social Psychology, 43(3), 450-461. https://doi. org/10.1037/0022-3514.43.3.450

Ryan, R. M., \& Deci, E. L. (2000). Intrinsic and extrinsic motivations: Classic definitions and new directions. Contemporary Educational Psychology, 25(1), 54-67. https://doi.org/10.1006/ceps. 1999.1020

Ryan, R. M., \& Deci, E. L. (2017). Self-determination theory: Basic psychological needs in motivation, development, and wellness. Guilford Publications.

Schneider, C. Q., \& Wagemann, C. (2012). Set-theoretic methods for the social sciences: A guide to qualitative comparative analysis. Cambridge University Press.

Seibert, S. E., Silver, S. R., \& Randolph, W. A. (2004). Taking empowerment to the next level: A multiple-level model of empowerment, performance, and satisfaction. Academy of Management Journal, 47(3), 332-349. https://doi.org/10.2307/20159 585

Shamir, B. (1991). Meaning, self and motivation in organizations. Organization Studies, 12(3), 405-424. https://doi.org/10.1177/ 017084069101200304

Sheldon, K. M., \& Elliot, A. J. (1999). Goal striving, need satisfaction, and longitudinal well-being: The self-concordance model Journal of Personality and Social Psychology, 76(3), 482-497. https://doi.org/10.1037/0022-3514.76.3.482

Slemp, G. R., Kern, M. L., Patrick, K. J., \& Ryan, R. M. (2018). Leader autonomy support in the workplace: A meta-analytic review. Motivation and Emotion, 42(5), 706-724. https://doi.org/10. 1007/s11031-018-9698-y

Spreitzer, G. M. (1995). Psychological empowerment in the workplace: Dimensions, measurement, and validation. Academy of Management Journal, 38(5), 1442-1465. https://doi.org/10.5465/256865

Spreitzer, G. M. (2008). Taking stock: A review of more than twenty years of research. In J. Barling \& C. L. Cooper (Eds.), The SAGE handbook of organizational behavior: Volume I micro approaches (pp. 54-72). SAGE.

Staufenbiel, T., \& Hartz, C. (2000). Organizational citizenship behavior: Entwicklung und erste Validierung eines Meßinstruments [Organizational citizenship behavior: Development and validation of a measurement instrument]. Diagnostica, 46(2), 73-83. https://doi.org/10.1026/0012-1924.46.2.73

Thomann, E., \& Maggetti, M. (2020). Designing research with qualitative comparative analysis (QCA): Approaches, challenges, and tools. Sociological Methods and Research, 49(2), 356-386. https://doi.org/10.1177/0049124117729700

Thomas, K. W., \& Velthouse, B. A. (1990). Cognitive elements of empowerment: An "interpretive" model of intrinsic task motivation. Academy of Management Review, 15(4), 666-681. https:// doi.org/10.5465/amr.1990.4310926

Van den Broeck, A., Ferris, D. L., Chang, C. H., \& Rosen, C. C. (2016). A review of self-determination theory's basic psychological needs at work. Journal of Management, 42(5), 1195-1229. https://doi.org/10.1177/0149206316632058

Van den Broeck, A., Lens, W., De Witte, H., \& Van Coillie, H. (2013). Unraveling the importance of the quantity and the quality of workers' motivation for well-being: A person-centered perspective. Journal of Vocational Behavior, 82(1), 69-78. https://doi. org/10.1016/j.jvb.2012.11.005

Van den Broeck, A., Vansteenkiste, M., De Witte, H., Soenens, B., \& Lens, W. (2010). Capturing autonomy, competence, and relatedness at work: Construction and initial validation of the Workrelated Basic Need Satisfaction scale. Journal of Occupational and Organizational Psychology, 83(4), 981-1002. https://doi. org/10.1348/096317909X481382

van Dijke, M., Leunissen, J. M., Wildschut, T., \& Sedikides, C. (2019). Nostalgia promotes intrinsic motivation and effort in the presence of low interactional justice. Organizational Behavior and Human Decision Processes, 150, 46-61. https://doi.org/10. 1016/j.obhdp.2018.12.003

Vansteenkiste, M., \& Ryan, R. M. (2013). On psychological growth and vulnerability: Basic psychological need satisfaction and need frustration as a unifying principle. Journal of Psychotherapy Integration, 23(3), 263-280. https://doi.org/10.1037/a0032359

von Collani, G., \& Schyns, B. (1999). Generalisierte Selbstwirksamkeitserwartung. Zusammenstellung Sozialwissenschaftlicher Items Und Skalen (ZIS). https://doi.org/10.6102/zis17

Warburton, V. E., Wang, J. C. K., Bartholomew, K. J., Tuff, R. L., \& Bishop, K. C. M. (2020). Need satisfaction and need frustration as distinct and potentially co-occurring constructs: Need profiles examined in physical education and sport. 
Motivation and Emotion, 44(1), 54-66. https://doi.org/10.1007/ s11031-019-09798-2

Waterman, A. S. (1993). Two conceptions of happiness: Contrasts of personal expressiveness (eudaimonia) and hedonic enjoyment. Journal of Personality and Social Psychology, 64(4), 678-691. https://doi.org/10.1037//0022-3514.64.4.678

Weinstein, N., Ryan, R. M., \& Deci, E. L. (2012). Motivation, meaning, and wellness: A self-determination perspective on the creation and internalization of personal meanings and life goals. In P. T. P. Wong (Ed.), The Human quest for meaning: Theories, research, and applications (pp. 81-106). Routledge.

Weyer, G., Hodapp, V., \& Neuhäuser, S. (1997). Subjektive Zufriedenheit und Belastung von Arbeit und Beruf. Zusammenstellung Sozialwissenschaftlicher Items Und Skalen (ZIS). https://doi. org/10.6102/zis3

Whitaker, R. G., Sperber, N., Baumgartner, M., Thiem, A., Cragun, D., Damschroder, L., Miech, E., Slade, A., \& Birken, S. (2020). Coincidence analysis: A new method for causal inference in implementation science. Implementation Science, 15(108), 1-10. https://doi.org/10.21203/rs.3.rs-30466/v1
White, R. W. (1959). Motivation reconsidered: The concept of competence. Psychological Review, 66(5), 297-333. https://doi.org/ 10.1037/h0040934

Yakovchenko, V., Miech, E. J., Chinman, M. J., Chartier, M., Gonzalez, R., Kirchner, J. E., Morgan, T. R., Park, A., Powell, B. J., Proctor, E. K., Ross, D., Waltz, T. J., \& Rogal, S. S. (2020). Strategy configurations directly linked to higher hepatitis c virus treatment starts. Medical Care, 58(5), e31-e38. https://doi.org/10.1097/ mlr.0000000000001319

Zapata-Phelan, C. P., Colquitt, J. A., Scott, B. A., \& Livingston, B. (2009). Procedural justice, interactional justice, and task performance: The mediating role of intrinsic motivation. Organizational Behavior and Human Decision Processes, 108(1), 93-105. https://doi.org/10.1016/j.obhdp.2008.08.001

Publisher's Note Springer Nature remains neutral with regard to jurisdictional claims in published maps and institutional affiliations. 